\title{
Docetaxel increases the risk of severe infections in the treatment of non-small cell lung cancer: a meta-analysis
}

\author{
Qingcheng $\mathrm{Du}^{1, *}$, Guanming Jiang ${ }^{2, *}$, Silu $\mathrm{Li}^{3}$, Yong Liu ${ }^{1,4}$, Zunnan Huang ${ }^{1,5}$ \\ ${ }^{1}$ School of Pharmacy, Guangdong Medical University, Dongguan, Guangdong 523808, China \\ 2 Department of Medical Oncology, Dongguan People's Hospital, Dongguan, Guangdong 523018, China \\ ${ }^{3}$ School of Basic Medicine, Guangdong Medical University, Dongguan, Guangdong 523808, China \\ ${ }^{4}$ Key Laboratory for Research and Development of Natural Drugs of Guangdong Province, Zhanjiang, Guangdong 524023, \\ China \\ ${ }^{5}$ Key Laboratory for Medical Molecular Diagnostics of Guangdong Province, Dongguan Scientific Research Center, Guangdong \\ Medical University, Guangdong 523808, China \\ * These authors contributed equally to this work. \\ Correspondence to: Yong Liu, email: liuyong0614@126.com; Zunnan Huang, email: zn_huang@yahoo.com \\ Keywords: docetaxel; infections; non-small cell lung cancer; mechanism; systematic review \\ Received: November 11,2017 Accepted: May 15, $2018 \quad$ Published: August 22, 2018 \\ Copyright: Du et al. This is an open-access article distributed under the terms of the Creative Commons Attribution License \\ 3.0 (CC BY 3.0), which permits unrestricted use, distribution, and reproduction in any medium, provided the original author and \\ source are credited.
}

\section{ABSTRACT}

The purpose of this study was to determine whether docetaxel increases the risk of severe infections in patients with non-small cell lung cancer. A thorough literature search of the PubMed, EMBASE and Cochrane Central Register of Controlled Trials databases was performed (up to February 28, 2017) without any language restrictions. In addition, we searched the www.clinicaltrials.gov website and checked each reference listed in the included studies, relevant reviews and guidelines. We also included randomized controlled trials that reported severe infections in patients with non-small cell lung cancer who were administered docetaxel. A metaanalysis was conducted using relative risk and random effects models in Stata 14.0 software. Sensitivity analysis and meta-regression were performed using Stata $\mathbf{1 4} .0$ software. We identified 354 records from the initial search, and this systematic review ultimately included 43 trials with 12,447 participants. The results of our metaanalysis showed that docetaxel increased the risk of severe infections [relative risk: 2.10, 95\% confidence interval: 1.51-2.93, $\left.I^{2}=69.6 \%, P=0.000\right]$. Meta-regression analysis indicated that the type of intervention was a major source of heterogeneity. Our systematic review and meta-analysis suggest that docetaxel is associated with the risk of severe infections.

\section{INTRODUCTION}

Lung cancer is a respiratory disease, one of the most common types of cancer, and the leading cause of cancer-associated death worldwide. Each year, there are more than 1.3 million new cases of lung cancer [1]. According to pathological classification systems, lung cancer is divided into small cell lung cancer and non-small cell lung cancer (NSCLC) $[2,3]$. NSCLC accounts for approximately $85 \%$ of lung cancer cases [4] and consists of three different subtypes: squamous cell carcinoma, large cell carcinoma and adenocarcinoma [2]. Most patients with NSCLC present with advanced or metastatic disease, and the main metastatic sites of NSCLC are the brain, bone, liver and adrenal glands $[4,5]$. The best treatment option for patients with NSCLC is surgery, and approximately $20 \%$ of these patients are good candidates for potentially curative resection [6]. However, even for patients who undergo a complete 
resection, the 5-year survival rate is only $40 \%$ [7]. Thus, NSCLC is a serious threat to human health.

The current common chemotherapy agents include cisplatin, carboplatin, gemcitabine, pemetrexed, paclitaxel and docetaxel [8]. Docetaxel, a paclitaxel derivative, is a second-generation taxane anticancer agent. Its main mechanisms of action include promoting tubulin binding, inhibiting its agglomeration, and significantly stabilizing its conformation, leading to cell cycle arrest during G2/M phase and consequent anti-tumor effects [9]. Compared to paclitaxel, docetaxel has better water solubility and fewer toxic side effects [10]. Moreover, docetaxel can reduce $\mathrm{Bcl} 2$ (anti-apoptosis) gene expression and promote the expression of the cell cycle regulator $\mathrm{p} 27$, which results in cancer cell apoptosis [11]. Docetaxel has synergistic effects with other chemotherapy agents in prostate cancer [12] and has been approved as a first-line treatment combined with cisplatin, as a single-dose second-line treatment, or as a single-dose maintenance treatment for advanced NSCLC patients in many countries [13-15]. Singledose docetaxel treatment is promising as first-line therapy for NSCLC patients with a poor performance status [15]. Furthermore, docetaxel is effective as a second-line therapy for metastatic NSCLC, extending progression-free survival and overall survival [16, 17]. Due to its beneficial effects and good tolerability, docetaxel plays an important role in the treatment of NSCLC [18]. However, some studies [19-22] have shown that docetaxel can increase the risk of adverse reactions, such as neutropenia, febrile neutropenia and anemia, in patients with advanced NSCLC. These adverse reactions have attracted attention from the research community.

Previous publications have explored the link between infections and docetaxel treatment [19, $21]$. For instance, some randomized controlled trials [23-25] reported that docetaxel increased the risk of severe infections in patients with NSCLC, while others [26-28] found that severe infections were not associated with docetaxel. Thus, a definitive conclusion has not been reached. Additionally, no previous systematic review or meta-analysis has been conducted to comprehensively assess the risk of severe infections ( $\geq$ grade 3 ) in docetaxel-treated patients with NSCLC. Therefore, we performed this study to determine whether docetaxel increases the risk of severe infections ( $\geq$ grade 3 ) in patients with NSCLC.

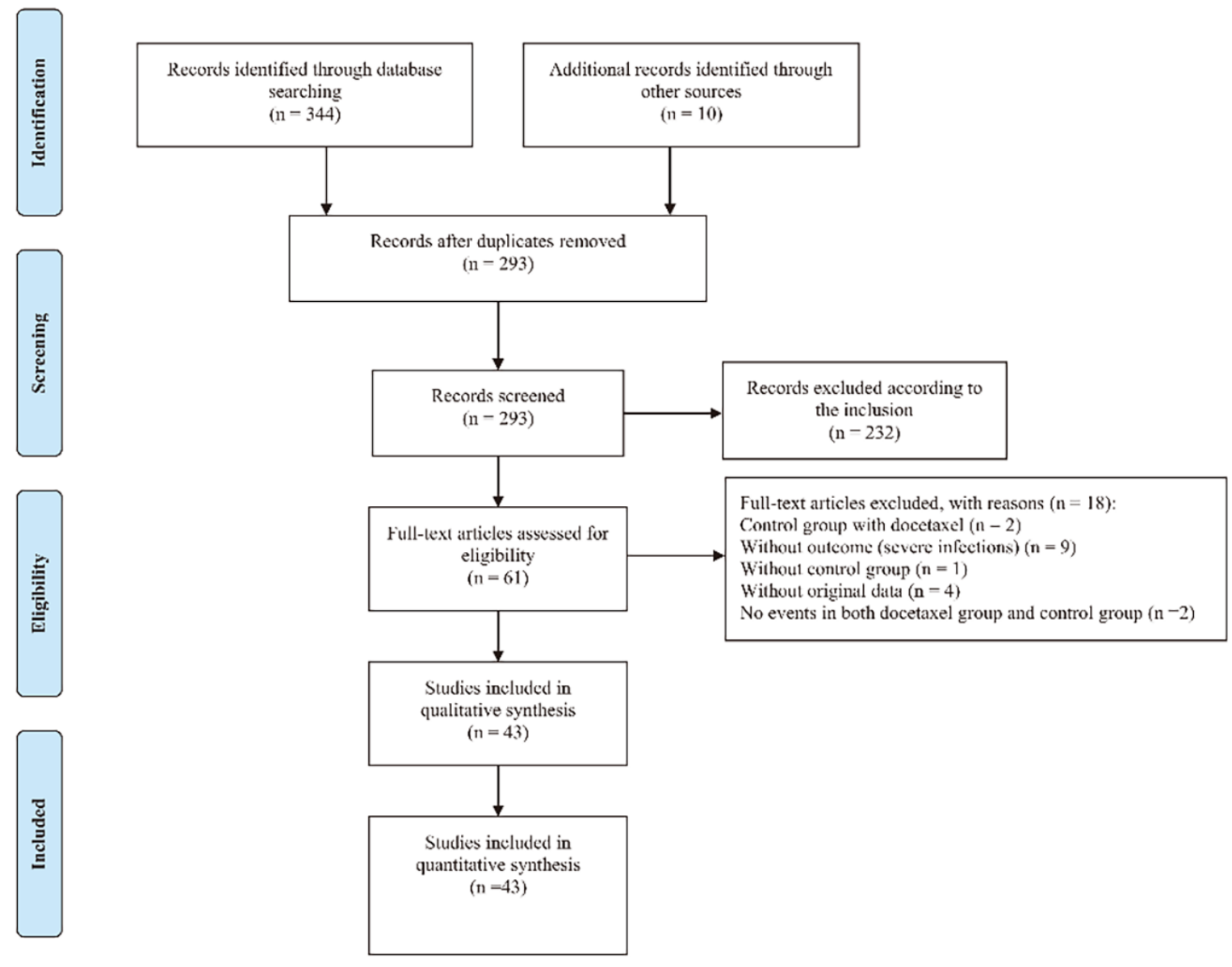

Figure 1: Flow diagram of study selection of all included randomized controlled trials. 


\section{RESULTS}

\section{Search results and trial descriptions}

The initial search identified 354 records and bibliographies of relevant reviews from electronic databases, including studies and guidelines, generated prior to February 28, 2017. A total of 293 trials were obtained after duplicates were removed. According to the inclusion and exclusion criteria, 232 trials were eliminated after title and abstract review. Thus, a total of 61 trials remained, and the full-text articles corresponding to these trials were obtained to further assess eligibility. After a careful review of these articles, 18 were excluded due to ineligibility or incomplete data. In the end, this systematic review included 43 studies with 12,447 participants, including 40 journal articles [23-62] and three trials (NCT00520676, NCT00191139, and NCT01204697) from the clinical trial registration website (https://clinicaltrials. gov). Details of the study selection are shown in (Figure 1).

The main characteristics of all 43 trials included in this meta-analysis are listed in (Table 1). Among all the included trials, 19 were phase II trials, and 24 were phase III trials. The sample size of these trials varied from 51 to 1,446 , and all participants were older than 50 years of age. While a $75 \mathrm{mg} / \mathrm{m}^{2}$ dose was typically used in the docetaxel-only group, the control group was given other drugs or supportive care. Most studies focused on stage IIIIV disease and on tumor histologies of adenocarcinoma, squamous cell carcinoma, bronchioalveolar carcinoma, and large cell carcinoma.

The risk of bias in all the included trials is summarized in (Figure 2). With respect to random
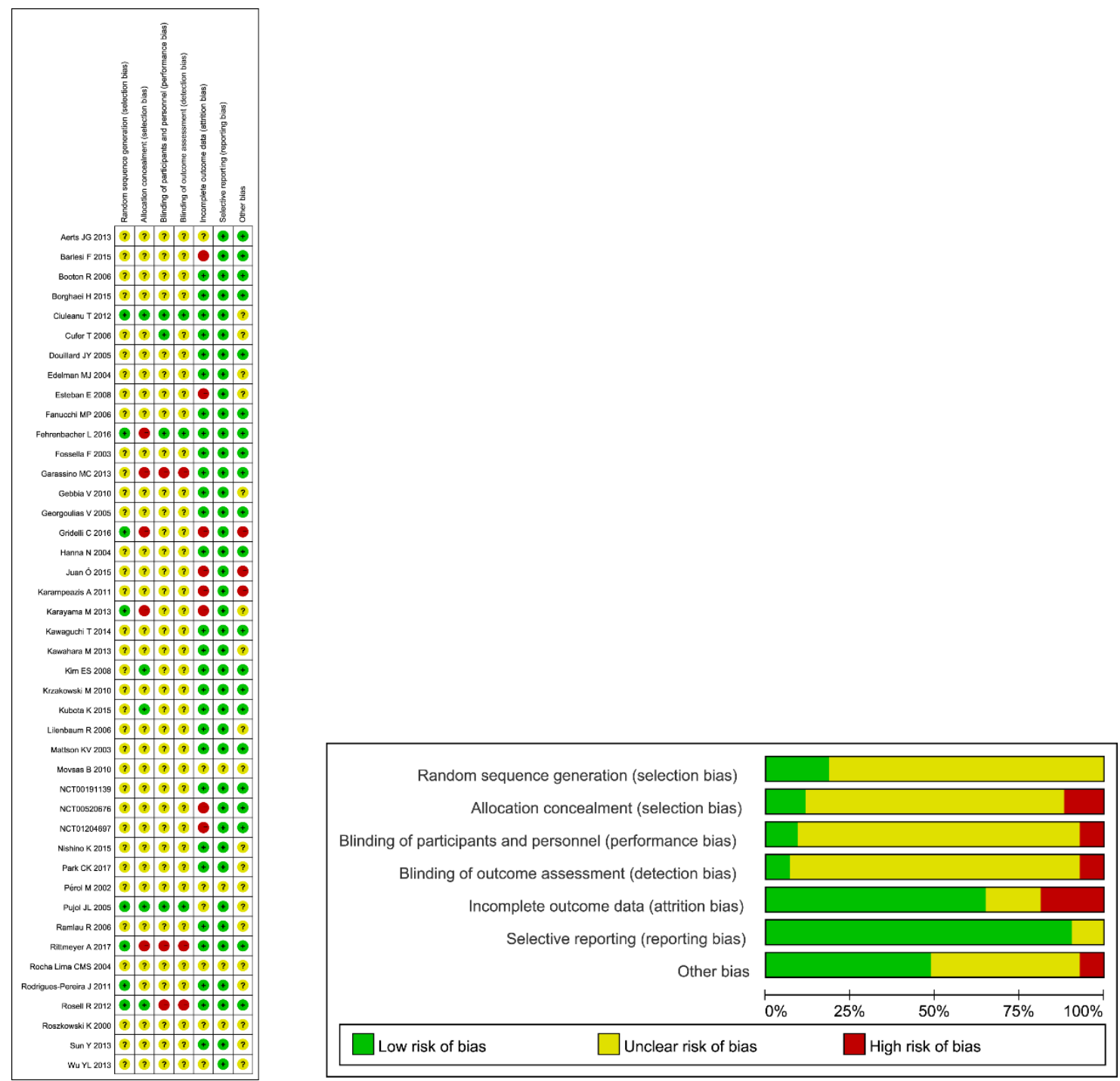

Figure 2: Risk of bias of each included trial as assessed using the risk of bias assessment tool. 
sequence generation, allocation concealment, blinding of participants and personnel, and blinding of outcome assessment, most trials showed an unclear risk of bias according to the authors' judgment. On the other hand, with respect to incomplete outcome data, selective reporting and other biases, most trials showed a low risk of bias.

\section{Relative risk (RR) of severe infections}

The meta-analysis of 43 randomized controlled trials indicated that docetaxel was related to a significant increase in the risk of severe infections. The RR of severe infections in NSCLC patients treated with docetaxel compared to that in controls was 2.10 (95\% confidence interval (CI): $1.51-2.93, I^{2}=69.6 \%, P=0.000$ ) (Figure $3)$. The heterogeneity among studies was significant $\left(I^{2}>\right.$ $50 \%$ ), and thus, the random effects model was selected.

\section{Subgroup analysis by age}

In the $\geq 60$ years age subgroup from a total of 24 trials and 6,835 participants, 391 patients had severe infections (279 in the docetaxel group and 112 in the control group), for a RR of 2.03 (95\% CI: 1.37-3.01, $P$ $=0.000)$. In the younger subgroup ( $<60$ years) from a total of 19 trials and 5,612 participants, 443 patients had severe infections (288 in the docetaxel group and 155 in the control group), for a RR of 2.12 (95\% CI: 1.20-3.74, $P=0.010)$. Thus, the subgroup analysis by age showed that docetaxel consistently increased the risk for severe infections in NSCLC patients (Table 2). The forest plot of this subgroup analysis is shown in (Supplementary Figure 1).

\section{Subgroup analysis by intervention type}

Subgroup analysis was also performed on the intervention type (docetaxel alone versus docetaxel with other interventions). The RR of severe infections was $3.26(95 \% \mathrm{CI}: 2.12-5.00, P=0.000)$ for the docetaxel alone group from a total of 15 trials and 4,865 individuals, 318 of whom had severe infections (250 in the docetaxel group and 68 in the control group). The RR was 1.62 (95\% CI: $1.09-2.39, P=0.016)$ for the group of patients who received additional drug interventions from a total of 28 trials and 7,582 individuals, 516 of whom had severe infections (317 in the docetaxel group and 199 in the control group). The subgroup analysis by intervention type again showed that docetaxel increased the risk of severe infections in NSCLC patients (Table 2 ). The forest plot of this subgroup analysis is shown in (Supplementary Figure 2).

\section{Subgroup analysis by docetaxel dosage}

In this subgroup analysis, we divided the 43 trials into two subgroups according to the docetaxel dosage $(\geq 75$ $\mathrm{mg} / \mathrm{m}^{2}$ versus $<75 \mathrm{mg} / \mathrm{m}^{2}$ ). In the higher dose subgroup $\left(\geq 75 \mathrm{mg} / \mathrm{m}^{2}\right)$ from 33 trials and 10,857 participants, 700 patients had severe infections (469 in the docetaxel group and 231 in the control group), yielding a RR of 2.00 (95\% CI: $1.40-2.87, P=0.000)$. For the lower dose subgroup $\left(<75 \mathrm{mg} / \mathrm{m}^{2}\right)$ from 10 trials and 1,590 participants, 134 patients had severe infections (98 in the docetaxel group and 36 in the control group), for a RR of 2.34 (95\% CI: $0.91-6.03, P=0.077)$. Thus, the subgroup analysis by docetaxel dosage showed that a higher dose of docetaxel $\left(\geq 75 \mathrm{mg} / \mathrm{m}^{2}\right)$ increased the likelihood of severe infections in NSCLC patients, while a lower dose of docetaxel $(<75$ $\left.\mathrm{mg} / \mathrm{m}^{2}\right)$ did not have a harmful effect on the development of severe infections (Table 2). The forest plot of this subgroup analysis is shown in (Supplementary Figure 3).

\section{Subgroup analysis by trial phase}

Finally, we performed a subgroup analysis according to trial phase (phase II versus III). The RR of severe infections was 1.69 (95\%: 0.97-2.96, $P=0.064$ ) from a total of 19 phase II trials and 2,138 individuals, including 217 with severe infections (125 in the docetaxel group and 92 in the control group). For the 24 phase III trials of 10,309 individuals, 617 patients had severe infections (442 in the docetaxel group and 175 in the control group), yielding a RR of 2.45 (95\% CI: 1.63-3.69, $P=0.000)$. The subgroup analysis by trial phase illustrated that docetaxel did not contribute to the risk of severe infections in NSCLC patients during phase II trials but did increase the risk of severe infections in NSCLC patients during phase III trials (Table 2). The forest plot of this subgroup analysis is shown in (Supplementary figure 4).

In addition, we performed a subgroup analysis according to disease stage (stages IIB and IV only vs mixed stages). The forest plot of this subgroup analysis is shown in (Supplementary figure 5).

\section{Meta-regression analysis}

The heterogeneity among the included studies was significant. Thus, we performed a meta-regression analysis to explore the source of heterogeneity. The metaregression analysis was performed using Stata 14.0 to analyze age, intervention type, docetaxel dosage, and trial phase. The result of our meta-regression analysis showed that age, docetaxel dosage and trial phase were not sources of heterogeneity $(P=0.983, P=0.960$, and $P=0.238$, respectively), while heterogeneity was indeed introduced by intervention type $(P=0.028)$. 
Table 1 Characteristics of each included study

\begin{tabular}{|c|c|c|c|c|c|c|}
\hline Study and year & Phase & Race & Intervention & Disease stage & Tumor histology & $\begin{array}{l}\text { Median } \\
\text { follow- } \\
\text { up }\end{array}$ \\
\hline Aerts JG 2013 & II & NR & $\begin{array}{l}\text { D: erlotinib } 150 \mathrm{mg}+ \\
\text { docetaxel } 75 \mathrm{mg} / \mathrm{m} 2+ \\
\text { pemetrexed } 500 \mathrm{mg} / \\
\mathrm{m} 2 \\
\mathrm{~N} \text { : erlotinib } 150 \mathrm{mg}\end{array}$ & $\begin{array}{l}\text { Stage IB, } \\
\text { IIIB, IV }\end{array}$ & $\begin{array}{l}\text { Squamous cell } \\
\text { carcinoma, } \\
\text { adenocarcinoma, } \\
\text { large cell, } \\
\text { undifferentiated, } \\
\text { bronchoalveolar, } \\
\text { plavelsel, other, } \\
\text { unknown }\end{array}$ & $\begin{array}{l}19 \\
\text { months }\end{array}$ \\
\hline Barlesi F 2015 & III & NR & $\begin{array}{l}\text { D: cisplatin } 75 \mathrm{mg} / \mathrm{m}^{2} \\
+ \text { docetaxel } 75 \mathrm{mg} / \mathrm{m}^{2} \\
\mathrm{~N}: \text { cisplatin } 75 \mathrm{mg} / \mathrm{m}^{2} \\
+ \text { gemcitabine } 1250 \\
\mathrm{mg} / \mathrm{m}^{2}\end{array}$ & Stage IB-III & $\begin{array}{l}\text { Adenocarcinoma } \\
\text { and squamous cell } \\
\text { carcinoma }\end{array}$ & $\begin{array}{l}20.2 \\
\text { months }\end{array}$ \\
\hline Booton R 2006 & III & NR & $\begin{array}{l}\text { D: docetaxel } 75 \mathrm{mg} / \mathrm{m}^{2} \text {, } \\
\text { carboplatin }(\mathrm{AUC}=6) \\
\mathrm{N} \text { : mitomycin } 6 \mathrm{mg} / \\
\mathrm{m}^{2} \text {, ifosfamide } 3 \mathrm{~g} / \mathrm{m}^{2} \\
+ \text { cisplatin } 50 \mathrm{mg} / \mathrm{m}^{2} \\
\text { or mitomycin } 6 \mathrm{mg} / \mathrm{m}^{2} \text {, } \\
\text { vinblastine } 6 \mathrm{mg} / \mathrm{m}^{2}+ \\
\text { cisplatin } 50 \mathrm{mg} / \mathrm{m}^{2}\end{array}$ & Stage III, IV & $\begin{array}{l}\text { Squamous cell } \\
\text { carcinoma, } \\
\text { adenocarcinoma, } \\
\text { large cell, } \\
\text { undifferentiated } \\
\text { non-small lung } \\
\text { cancer }\end{array}$ & $\begin{array}{l}17.4 \\
\text { months }\end{array}$ \\
\hline $\begin{array}{l}\text { Borghaei H } \\
2015\end{array}$ & III & $\begin{array}{l}\text { White, } \\
\text { Black, } \\
\text { Asian, } \\
\text { Other }\end{array}$ & $\begin{array}{l}\text { D: docetaxel } 75 \mathrm{mg} / \mathrm{m}^{2} \\
\mathrm{~N} \text { : nivolumab } 3 \mathrm{mg} / \mathrm{kg}\end{array}$ & $\begin{array}{l}\text { Stage IIIB, } \\
\text { IV }\end{array}$ & $\begin{array}{l}\text { Squamous cell } \\
\text { carcinoma }\end{array}$ & $\begin{array}{l}9.2 \\
\text { months }\end{array}$ \\
\hline $\begin{array}{l}\text { Ciuleanu T } \\
2012\end{array}$ & III & $\begin{array}{l}\text { Caucasian, } \\
\text { Asian, } \\
\text { other }\end{array}$ & $\begin{array}{l}\text { D: chemotherapy } \\
\left(\text { docetaxel } 75 \mathrm{mg} / \mathrm{m}^{2} \text {, }\right. \\
\text { pemetrexed regimens) } \\
\text { N: erlotinib } 150 \mathrm{mg}\end{array}$ & $\begin{array}{l}\text { Stage IIIB, } \\
\text { IV }\end{array}$ & $\begin{array}{l}\text { Adenocarcinoma, } \\
\text { squamous cell } \\
\text { carcinoma, other }\end{array}$ & $\begin{array}{l}27.9 \\
\text { months }\end{array}$ \\
\hline Cufer T 2006 & II & $\begin{array}{l}\text { Caucasian, } \\
\text { Black, } \\
\text { Asian, } \\
\text { Oriental, } \\
\text { Other }\end{array}$ & $\begin{array}{l}\text { D: docetaxel } 75 \mathrm{mg} / \mathrm{m}^{2} \\
\mathrm{~N}: \text { gefitinib } 250 \mathrm{mg}\end{array}$ & $\begin{array}{l}\text { Stage IIIB, } \\
\text { IV }\end{array}$ & NR & $\begin{array}{l}9.4 \\
\text { months }\end{array}$ \\
\hline $\begin{array}{l}\text { Douillard JY } \\
2005\end{array}$ & II & NR & $\begin{array}{l}\mathrm{D}: \text { docetaxel } 75 \mathrm{mg} / \mathrm{m}^{2} \\
+ \text { cisplatin } 100 \mathrm{mg} / \mathrm{m}^{2} \\
\mathrm{~N}: \text { vinorelbine } 30 \mathrm{mg} / \\
\mathrm{m}^{2}+\text { cisplatin } 100 \mathrm{mg} / \\
\mathrm{m}^{2}\end{array}$ & Stage IV & $\begin{array}{l}\text { Squamous, } \\
\text { adenocarcinoma, } \\
\text { large cell } \\
\text { carcinoma, } \\
\text { undifferentiated } \\
\text { lung cancer, mixed } \\
\text { histological subtype }\end{array}$ & $\begin{array}{l}8.8 \\
\text { months }\end{array}$ \\
\hline
\end{tabular}




\begin{tabular}{|c|c|c|c|c|c|c|}
\hline $\begin{array}{l}\text { Edelman MJ } \\
2004\end{array}$ & II & NR & $\begin{array}{l}\text { D: docetaxel } 75-100 \\
\mathrm{mg} / \mathrm{m}^{2}+\text { cisplatin } 100 \\
\mathrm{mg} / \mathrm{m}^{2}+\text { vinorelbine } \\
25 \mathrm{mg} / \mathrm{m}^{2} \\
\mathrm{~N}: \text { carboplatin } 5.5 \mathrm{mg} / \\
\mathrm{ml} / \mathrm{min}+\text { gemcitabine } \\
1,000 \mathrm{mg} / \mathrm{m}^{2}+ \\
\text { paclitaxel } 225 \mathrm{mg} / \mathrm{m}^{2}\end{array}$ & $\begin{array}{l}\text { Stage IIIB, } \\
\text { IV }\end{array}$ & $\begin{array}{l}\text { Squamous, } \\
\text { adenocarcinoma, } \\
\text { large cell } \\
\text { carcinoma, other }\end{array}$ & NR \\
\hline $\begin{array}{l}\text { Esteban E } \\
2008\end{array}$ & II & NR & $\begin{array}{l}\text { D: gemcitabine } 1,000 \\
\mathrm{mg} / \mathrm{m}^{2}+\text { docetaxel } 35 \\
\mathrm{mg} / \mathrm{m}^{2} \\
\mathrm{~N}: \text { gemcitabine } 1,000 \\
\mathrm{mg} / \mathrm{m}^{2}+\text { vinorelbine } \\
25 \mathrm{mg} / \mathrm{m} 2\end{array}$ & $\begin{array}{l}\text { Stage IIIB, } \\
\text { IV }\end{array}$ & $\begin{array}{l}\text { Squamous, } \\
\text { adenocarcinoma, } \\
\text { large cell carcinoma }\end{array}$ & $\begin{array}{l}9.5 \\
\text { months }\end{array}$ \\
\hline $\begin{array}{l}\text { Fanucchi MP } \\
2006\end{array}$ & II & $\begin{array}{l}\text { White, } \\
\text { Black, } \\
\text { Asian/ } \\
\text { Pacific } \\
\text { Islander, } \\
\text { Hispanic, } \\
\text { Other }\end{array}$ & $\begin{array}{l}\text { D: bortezomib } 1.3 \mathrm{mg} / \\
\mathrm{m}^{2}+\text { docetaxel } 75 \mathrm{mg} / \\
\mathrm{m}^{2} \\
\mathrm{~N} \text { : bortezomib } 1.5 \mathrm{mg} / \\
\mathrm{m}^{2}\end{array}$ & $\begin{array}{l}\text { Stage IIIB, } \\
\text { IV }\end{array}$ & $\begin{array}{l}\text { Adenocarcinoma, } \\
\text { squamous cell, } \\
\text { bronchioalveolar, } \\
\text { large cell, } \\
\text { adenosquamous, } \\
\text { epithelioid } \\
\text { carcinoma, } \\
\text { unknown }\end{array}$ & NR \\
\hline $\begin{array}{l}\text { Fehrenbacher } \\
\text { L } 2016\end{array}$ & II & NR & $\begin{array}{l}\mathrm{D}: \text { docetaxel } 75 \mathrm{mg} / \mathrm{m}^{2} \\
\mathrm{~N}: \text { atezolizumab } 1200 \\
\mathrm{mg}\end{array}$ & $\begin{array}{l}\text { Stage IIIB, } \\
\text { IV, recurrent }\end{array}$ & $\begin{array}{l}\text { Non-squamous and } \\
\text { squamous }\end{array}$ & $\begin{array}{l}14.8 \\
\text { months }\end{array}$ \\
\hline $\begin{array}{l}\text { Fossella F } \\
2003\end{array}$ & III & NR & $\begin{array}{l}\mathrm{D}: \text { docetaxel } 75 \mathrm{mg} / \\
\mathrm{m}^{2}+\text { cisplatin } 75 \mathrm{mg} / \\
\mathrm{m}^{2}+\text { carboplatin } 6 \mathrm{mg} / \\
\mathrm{mL} / \mathrm{min} \\
\mathrm{N}: \text { vinorelbine } 25 \mathrm{mg} / \\
\mathrm{m}^{2}+\text { cisplatin } 100 \mathrm{mg} / \\
\mathrm{m}^{2}\end{array}$ & $\begin{array}{l}\text { Locally } \\
\text { advanced, } \\
\text { stage IIIB, } \\
\text { metastatic, } \\
\text { stage IV }\end{array}$ & $\begin{array}{l}\text { Adenocarcinoma, } \\
\text { large cell, } \\
\text { squamous cell, } \\
\text { bronchioalveolar } \\
\text { carcinoma, other }\end{array}$ & $\begin{array}{l}10 \\
\text { months }\end{array}$ \\
\hline $\begin{array}{l}\text { Garassino MC } \\
2013\end{array}$ & III & $\begin{array}{l}\text { White, } \\
\text { Asian }\end{array}$ & $\begin{array}{l}\text { D: docetaxel } 75 \mathrm{mg} / \mathrm{m}^{2} \\
\text { or } 35 \mathrm{mg} / \mathrm{m}^{2} \\
\text { N: erlotinib } 150 \mathrm{mg}\end{array}$ & $\begin{array}{l}\text { Locally } \\
\text { advanced or } \\
\text { metastatic }\end{array}$ & $\begin{array}{l}\text { Adenocarcinoma, } \\
\text { large cell, } \\
\text { squamous cell, } \\
\text { bronchioalveolar } \\
\text { carcinoma, other }\end{array}$ & $\begin{array}{l}33 \\
\text { months }\end{array}$ \\
\hline Gebbia V 2010 & II & NR & $\begin{array}{l}\text { D: cisplatin } 75 \mathrm{mg} / \mathrm{m}^{2} \\
+ \text { docetaxel } 75 \mathrm{mg} / \mathrm{m}^{2} \\
\mathrm{~N}: \text { cisplatin } 80 \mathrm{mg} / \mathrm{m}^{2} \\
+ \text { vinorelbine } 30 \mathrm{mg} / \\
\mathrm{m}^{2}\end{array}$ & $\begin{array}{l}\text { Stage IIIB, } \\
\text { IV }\end{array}$ & $\begin{array}{l}\text { Squamous, } \\
\text { adenocarcinoma, } \\
\text { large cell carcinoma }\end{array}$ & NR \\
\hline $\begin{array}{l}\text { Georgoulias V } \\
2005\end{array}$ & III & NR & $\begin{array}{l}\text { D: gemcitabine } 1,000 \\
\mathrm{mg} / \mathrm{m}^{2}+\text { docetaxel } 100 \\
\mathrm{mg} / \mathrm{m}^{2} \\
\mathrm{~N}: \text { vinorelbine } 30 \mathrm{mg} / \\
\mathrm{m}^{2}+\text { cisplatin } 80 \mathrm{mg} / \\
\mathrm{m}^{2}\end{array}$ & $\begin{array}{l}\text { Stage IIIB, } \\
\text { IV }\end{array}$ & $\begin{array}{l}\text { Squamous, } \\
\text { adenocarcinoma, } \\
\text { large cell } \\
\text { carcinoma, } \\
\text { undifferentiated, } \\
\text { mixed }\end{array}$ & $\begin{array}{l}9.0 \\
\text { months }\end{array}$ \\
\hline
\end{tabular}




\begin{tabular}{|c|c|c|c|c|c|c|}
\hline $\begin{array}{l}\text { Gridelli C } \\
2016\end{array}$ & II & NR & $\begin{array}{l}\text { D: erlotinib } 150 \mathrm{mg}+ \\
\text { docetaxel } 75 \mathrm{mg} / \mathrm{m}^{2} \\
\mathrm{~N} \text { : erlotinib } 150 \mathrm{mg}\end{array}$ & $\begin{array}{l}\text { Stage IIIB, } \\
\text { IV }\end{array}$ & $\begin{array}{l}\text { Squamous cell } \\
\text { carcinoma }\end{array}$ & NR \\
\hline Hanna N 2004 & III & NR & $\begin{array}{l}\mathrm{D}: \text { docetaxel } 75 \mathrm{mg} / \mathrm{m}^{2} \\
\mathrm{~N}: \text { pemetrexed } 500 \\
\mathrm{mg} / \mathrm{m}^{2}\end{array}$ & Stage III, IV & $\begin{array}{l}\text { Adenocarcinoma, } \\
\text { squamous cell } \\
\text { carcinoma }\end{array}$ & $\begin{array}{l}7.5 \\
\text { months }\end{array}$ \\
\hline Juan Ó 2015 & II & NR & $\begin{array}{l}\text { D: erlotinib } 150 \mathrm{mg}+ \\
\text { docetaxel } 75 \mathrm{mg} / \mathrm{m}^{2} \\
\mathrm{~N} \text { : erlotinib } 150 \mathrm{mg}\end{array}$ & $\begin{array}{l}\text { Stage IIIB, } \\
\text { IV }\end{array}$ & $\begin{array}{l}\text { Adenocarcinoma, } \\
\text { squamous } \\
\text { cell, large cell } \\
\text { carcinoma, } \\
\text { non-small cell } \\
\text { carcinoma }\end{array}$ & $\begin{array}{l}6.2 \\
\text { months }\end{array}$ \\
\hline $\begin{array}{l}\text { Karampeazis A } \\
2011\end{array}$ & III & NR & $\begin{array}{l}\mathrm{D}: \text { docetaxel } 38 \mathrm{mg} / \mathrm{m}^{2} \\
\mathrm{~N} \text { : vinorelbine } 25 \mathrm{mg} / \\
\mathrm{m}^{2}\end{array}$ & $\begin{array}{l}\text { Stage IIIB, } \\
\text { IV }\end{array}$ & $\begin{array}{l}\text { Squamous, } \\
\text { adenocarcinoma, } \\
\text { large cell } \\
\text { carcinoma. } \\
\text { undifferentiated }\end{array}$ & $\begin{array}{l}40.5 \\
\text { months }\end{array}$ \\
\hline $\begin{array}{l}\text { Karayama M } \\
2013\end{array}$ & II & NR & $\begin{array}{l}\mathrm{D}: \text { docetaxel } 60 \mathrm{mg} / \mathrm{m}^{2} \\
\mathrm{~N}: \text { pemetrexed } 500 \\
\mathrm{mg} / \mathrm{m}^{2}\end{array}$ & $\begin{array}{l}\text { Stage IIIB, } \\
\text { IV }\end{array}$ & $\begin{array}{l}\text { adenocarcinoma, } \\
\text { other }\end{array}$ & $\begin{array}{l}16.8 \\
\text { months }\end{array}$ \\
\hline $\begin{array}{l}\text { Kawaguchi T } \\
2014\end{array}$ & III & NR & $\begin{array}{l}\text { D: docetaxel } 60 \mathrm{mg} / \mathrm{m}^{2} \\
\mathrm{~N} \text { : erlotinib } 150 \mathrm{mg}\end{array}$ & $\begin{array}{l}\text { Stage IIIB, } \\
\text { IV }\end{array}$ & $\begin{array}{l}\text { Adenocarcinoma, } \\
\text { squamous cell } \\
\text { carcinoma, other }\end{array}$ & $\begin{array}{l}8.9 \\
\text { months }\end{array}$ \\
\hline $\begin{array}{l}\text { Kawahara M } \\
2013\end{array}$ & II & NR & $\begin{array}{l}\text { D: docetaxel } 60 \mathrm{mg} / \\
\mathrm{m}^{2}+\text { carboplatin }(\mathrm{AUC} \\
=6 \text { ) } \\
\mathrm{N}: \text { paclitaxel } 200 \mathrm{mg} / \\
\mathrm{m}^{2}+\text { carboplatin }(\mathrm{AUC} \\
=6)\end{array}$ & $\begin{array}{l}\text { Stage IIIB, } \\
\text { IV }\end{array}$ & $\begin{array}{l}\text { Squamous cell, } \\
\text { adenocarcinoma, } \\
\text { large cell carcinoma }\end{array}$ & $\begin{array}{l}15.8 \\
\text { months }\end{array}$ \\
\hline Kim ES 2008 & III & $\begin{array}{l}\text { White, } \\
\text { Asian, } \\
\text { Black, } \\
\text { Other }\end{array}$ & $\begin{array}{l}\text { D: docetaxel } 75 \mathrm{mg} / \mathrm{m}^{2} \\
\mathrm{~N} \text { : gefitinib } 250 \mathrm{mg}\end{array}$ & $\begin{array}{l}\text { Stage 0/I, } \\
\text { IIa/IIb, IIIa, } \\
\text { IIIb, IV, not } \\
\text { recorded }\end{array}$ & $\begin{array}{l}\text { Adenocarcinoma, } \\
\text { bronchoalveolar, } \\
\text { squamous cell, } \\
\text { large cell, mixed, } \\
\text { undifferentiated, } \\
\text { other }\end{array}$ & $\begin{array}{l}7.6 \\
\text { months }\end{array}$ \\
\hline $\begin{array}{l}\text { Krzakowski M } \\
2010\end{array}$ & III & NR & $\begin{array}{l}\mathrm{D}: \text { docetaxel } 75 \mathrm{mg} / \mathrm{m}^{2} \\
\mathrm{~N} \text { : vinflunine } 320 \mathrm{mg} / \\
\mathrm{m}^{2}\end{array}$ & $\begin{array}{l}\text { Stage IIIB, } \\
\text { IV, other }\end{array}$ & $\begin{array}{l}\text { Squamous cell, } \\
\text { adenocarcinoma } \\
\text { carcinoma, other }\end{array}$ & NR \\
\hline $\begin{array}{l}\text { Kubota K } \\
2015\end{array}$ & III & Japanese & $\begin{array}{l}\text { D: docetaxel } 60 \mathrm{mg} / \mathrm{m}^{2} \\
\text { + cisplatin } 80 \mathrm{mg} / \mathrm{m}^{2} \\
\mathrm{~N}: \text { S-1 } 80 \mathrm{mg} / \mathrm{m}^{2} / \text { day }+ \\
\text { cisplatin } 60 \mathrm{mg} / \mathrm{m}^{2}\end{array}$ & $\begin{array}{l}\text { Stage } \\
\text { IIIB, IV, } \\
\text { postoperative, } \\
\text { recurrence }\end{array}$ & $\begin{array}{l}\text { Adenocarcinoma, } \\
\text { squamous } \\
\text { cell, large cell } \\
\text { carcinoma, } \\
\text { adenosquamous, } \\
\text { other }\end{array}$ & NR \\
\hline
\end{tabular}




\begin{tabular}{|c|c|c|c|c|c|c|}
\hline $\begin{array}{l}\text { Lilenbaum R } \\
2006\end{array}$ & II & $\begin{array}{l}\text { White, } \\
\text { Black, } \\
\text { Asian/ } \\
\text { Pacific } \\
\text { Islander, } \\
\text { Hispanic, } \\
\text { Other }\end{array}$ & $\begin{array}{l}\text { D: irinotecan } 60 \mathrm{mg} / \mathrm{m}^{2} \\
+ \text { docetaxel } 35 \mathrm{mg} / \mathrm{m}^{2} \\
+ \text { celecoxib } 400 \mathrm{mg} \\
\mathrm{N}: \text { irinotecan } 100 \mathrm{mg} / \\
\mathrm{m}^{2}+\text { gemcitabine } \\
1,000 \mathrm{mg} / \mathrm{m}^{2}+ \\
\text { celecoxib } 400 \mathrm{mg}\end{array}$ & $\begin{array}{l}\text { Stage IIIB, } \\
\text { IV }\end{array}$ & NR & NR \\
\hline $\begin{array}{l}\text { Mattson KV } \\
2003\end{array}$ & III & NR & $\begin{array}{l}\text { D: docetaxel } 100 \mathrm{mg} / \\
\mathrm{m}^{2} \\
\mathrm{~N}: \text { no chemotherapy }\end{array}$ & $\begin{array}{l}\text { Stage IIIA } \\
\text { T3, IIIA, N2, } \\
\text { IIIB }\end{array}$ & $\begin{array}{l}\text { Squamous cell, } \\
\text { adenocarcinoma, } \\
\text { large cell } \\
\text { carcinoma, other }\end{array}$ & NR \\
\hline $\begin{array}{l}\text { Movsas B } \\
2010\end{array}$ & II & $\begin{array}{l}\text { Caucasian, } \\
\text { Asian, } \\
\text { Other }\end{array}$ & $\begin{array}{l}\text { D: gemcitabine } 1,000 \\
\mathrm{mg} / \mathrm{m}^{2}+\text { docetaxel } 75 \\
\mathrm{mg} / \mathrm{m}^{2} \\
\mathrm{~N}: \text { gemcitabine } 1,000 \\
\mathrm{mg} / \mathrm{m}^{2}\end{array}$ & $\begin{array}{l}\text { Stage } \\
\text { IIIA, IIIB, } \\
\text { unavailable }\end{array}$ & $\begin{array}{l}\text { Squamous, } \\
\text { adenocarcinoma, } \\
\text { large cell, mixed, } \\
\text { other }\end{array}$ & $\begin{array}{l}41.5 \\
\text { months }\end{array}$ \\
\hline NCT00191139 & II & $\begin{array}{l}\text { Caucasian, } \\
\text { Black } \\
\text { Asian, } \\
\text { Hispanic }\end{array}$ & $\begin{array}{l}\text { D: docetaxel } 75 \mathrm{mg} / \mathrm{m} 2 \\
+ \text { gemcitabine } 1,000 \\
\mathrm{mg} / \mathrm{m} 2 \\
\mathrm{~N}: \text { gemcitabine } 1,000 \\
\mathrm{mg} / \mathrm{m} 2\end{array}$ & Stage III & NR & NR \\
\hline NCT00520676 & III & $\begin{array}{l}\text { Taiwanese, } \\
\text { Mexican, } \\
\text { Brazilian, } \\
\text { Australian, } \\
\text { Chinese, } \\
\text { Korean }\end{array}$ & $\begin{array}{l}\text { D: docetaxel } 75 \mathrm{mg} / \mathrm{m} 2 \\
+ \text { carboplatin }(\mathrm{AUC} \\
=5) \\
\mathrm{N}: \text { pemetrexed } 500 \\
\mathrm{mg} / \mathrm{m} 2+\text { carboplatin } \\
(\mathrm{AUC}=5)\end{array}$ & $\begin{array}{l}\text { Stage IIIB, } \\
\text { IV }\end{array}$ & $\begin{array}{l}\text { Adenocarcinoma, } \\
\text { large cell carcinoma }\end{array}$ & NR \\
\hline NCT01204697 & II & NR & $\begin{array}{l}\text { D: docetaxel } 75 \mathrm{mg} / \mathrm{m} 2 \\
\text { plus erlotinib } 150 \mathrm{mg} \\
\text { N: erlotinib } 150 \mathrm{mg}\end{array}$ & $\begin{array}{l}\text { locally } \\
\text { advanced } \\
\text { (stage IIIB), } \\
\text { metastatic } \\
\text { (stage IV), } \\
\text { recurrent }\end{array}$ & $\begin{array}{l}\text { Squamous cell } \\
\text { carcinoma }\end{array}$ & NR \\
\hline $\begin{array}{l}\text { Nishino K } \\
2015\end{array}$ & II & NR & $\begin{array}{l}\text { D: docetaxel } 60 \mathrm{mg} / \\
\mathrm{m}^{2}+\text { bevacizumab } 15 \\
\mathrm{mg} / \mathrm{kg} \\
\mathrm{N}: \mathrm{S}-140 \mathrm{mg} / \mathrm{m}^{2}+ \\
\text { bevacizumab } 15 \mathrm{mg} / \mathrm{kg}\end{array}$ & $\begin{array}{l}\text { Stage IIIB, } \\
\text { IV }\end{array}$ & $\begin{array}{l}\text { Adenocarcinoma, } \\
\text { unclassified } \\
\text { non-small cell } \\
\text { carcinoma }\end{array}$ & $\begin{array}{l}14.6 \\
\text { months }\end{array}$ \\
\hline Park CK 2017 & III & NR & $\begin{array}{l}\text { D: docetaxel } 60 \mathrm{mg} / \mathrm{m}^{2} \\
\text { + cisplatin } 70 \mathrm{mg} / \mathrm{m}^{2} \\
\mathrm{~N}: \text { pemetrexed } 500 \\
\mathrm{mg} / \mathrm{m}^{2}+\text { cisplatin } 70 \\
\mathrm{mg} / \mathrm{m}^{2}\end{array}$ & $\begin{array}{l}\text { Stage IIIB, } \\
\text { IV }\end{array}$ & $\begin{array}{l}\text { Adenocarcinoma, } \\
\text { large cell carcinoma }\end{array}$ & NR \\
\hline Pérol M 2002 & II & NR & $\begin{array}{l}\mathrm{D} \text { : docetaxel } 100 \mathrm{mg} / \\
\mathrm{m}^{2}+\text { cisplatin } 100 \mathrm{mg} / \\
\mathrm{m}^{2}+\text { vinorelbine } 30 \\
\mathrm{mg} / \mathrm{m}^{2} \\
\mathrm{~N}: \text { cisplatin } 80 \mathrm{mg} / \mathrm{m}^{2} \\
+ \text { vinorelbine } 30 \mathrm{mg} / \\
\mathrm{m}^{2}\end{array}$ & Stage IV & $\begin{array}{l}\text { Epidermoid, } \\
\text { adenocarcinoma, } \\
\text { large cell carcinoma }\end{array}$ & $\begin{array}{l}103 \\
\text { weeks }\end{array}$ \\
\hline
\end{tabular}




\begin{tabular}{|c|c|c|c|c|c|c|}
\hline Pujol JL 2005 & III & NR & $\begin{array}{l}\mathrm{D} \text { : gemcitabine } 1,000 \\
\mathrm{mg} / \mathrm{m}^{2}+\text { docetaxel } 85 \\
\mathrm{mg} / \mathrm{m}^{2} \\
\mathrm{~N}: \text { cisplatin } 100 \mathrm{mg} / \\
\mathrm{m}^{2}+\text { vinorelbine } 30 \\
\mathrm{mg} / \mathrm{m}^{2}\end{array}$ & $\begin{array}{l}\text { Stage IIIB, } \\
\text { IV }\end{array}$ & $\begin{array}{l}\text { Squamous cell, } \\
\text { adenocarcinoma, } \\
\text { large cell carcinoma }\end{array}$ & NR \\
\hline $\begin{array}{l}\text { Ramlau R } \\
2006\end{array}$ & III & $\begin{array}{l}\text { White, } \\
\text { Oriental, } \\
\text { Black, } \\
\text { Other }\end{array}$ & $\begin{array}{l}\mathrm{D}: \text { docetaxel } 75 \mathrm{mg} / \mathrm{m}^{2} \\
\mathrm{~N}: \text { topotecan } 2.3 \mathrm{mg} / \\
\mathrm{m}^{2}\end{array}$ & $\begin{array}{l}\text { Stage IIIB, } \\
\text { IV }\end{array}$ & $\begin{array}{l}\text { Adenocarcinoma, } \\
\text { squamous cell large } \\
\text { cell carcinoma, } \\
\text { other }\end{array}$ & NR \\
\hline $\begin{array}{l}\text { Rittmeyer A } \\
2017\end{array}$ & III & $\begin{array}{l}\text { White, } \\
\text { Asian, } \\
\text { Black, } \\
\text { Other }\end{array}$ & $\begin{array}{l}\mathrm{D}: \text { docetaxel } 75 \mathrm{mg} / \mathrm{m}^{2} \\
\mathrm{~N} \text { : atezolizumab 1,200 } \\
\mathrm{mg}\end{array}$ & $\begin{array}{l}\text { Stage IIIB, } \\
\text { IV }\end{array}$ & $\begin{array}{l}\text { Non-squamous, } \\
\text { squamous } \\
\text { carcinoma }\end{array}$ & $\begin{array}{l}21 \\
\text { months }\end{array}$ \\
\hline $\begin{array}{l}\text { Rocha Lima } \\
\text { CMS } 2004\end{array}$ & II & NR & $\begin{array}{l}\mathrm{D}: \text { gemcitabine } 1,000 \\
\mathrm{mg} / \mathrm{m}^{2}+\text { docetaxel } 40 \\
\mathrm{mg} / \mathrm{m}^{2} \\
\mathrm{~N}: \text { gemcitabine } 1,000 \\
\mathrm{mg} / \mathrm{m}^{2}+\text { irinotecan } 100 \\
\mathrm{mg} / \mathrm{m}^{2}\end{array}$ & $\begin{array}{l}\text { Stage IIIB, } \\
\text { IV }\end{array}$ & $\begin{array}{l}\text { Adenocarcinoma, } \\
\text { squamous cell, } \\
\text { undifferentiated } \\
\text { large cell, } \\
\text { bronchoalveolar, } \\
\text { undifferentiated } \\
\text { non-small cell } \\
\text { carcinoma }\end{array}$ & $\begin{array}{l}20 \\
\text { months }\end{array}$ \\
\hline $\begin{array}{l}\text { Rodrigues- } \\
\text { Pereira J } 2011\end{array}$ & III & $\begin{array}{l}\text { East Asian, } \\
\text { Caucasian, } \\
\text { Hispanic, } \\
\text { African }\end{array}$ & $\begin{array}{l}\text { D: carboplatin (AUC } \\
=5)+ \text { docetaxel } 75 \\
\mathrm{mg} / \mathrm{m}^{2} \\
\mathrm{~N}: \text { carboplatin }(\mathrm{AUC} \\
=5)+ \text { pemetrexed } 500 \\
\mathrm{mg} / \mathrm{m}^{2}\end{array}$ & $\begin{array}{l}\text { Stage IIIB, } \\
\text { IV }\end{array}$ & $\begin{array}{l}\text { Adenocarcinoma, } \\
\text { large cell carcinoma }\end{array}$ & $\begin{array}{l}23.9 \\
\text { months }\end{array}$ \\
\hline Rosell R 2012 & III & NR & $\begin{array}{l}\text { D: cisplatin } 75 \mathrm{mg} / \mathrm{m}^{2} \\
+ \text { docetaxel } 75 \mathrm{mg} / \mathrm{m}^{2} \\
+ \text { gemcitabine } 1250 \\
\mathrm{mg} / \mathrm{m}^{2} \\
\mathrm{~N} \text { : erlotinib } 150 \mathrm{mg}\end{array}$ & $\begin{array}{l}\text { Stage N3, } \\
\text { IIIA, IIIB, IV }\end{array}$ & $\begin{array}{l}\text { Adenocarcinoma, } \\
\text { bronchoalveolar, } \\
\text { squamous cell } \\
\text { carcinoma, large } \\
\text { cell, other }\end{array}$ & $\begin{array}{l}18.9 \\
\text { months }\end{array}$ \\
\hline $\begin{array}{l}\text { Roszkowski K } \\
2000\end{array}$ & III & NR & $\begin{array}{l}\mathrm{D}: \text { docetaxel } 100 \mathrm{mg} / \\
\mathrm{m}^{2}+\text { best supportive } \\
\text { care } \\
\mathrm{N} \text { : best supportive care }\end{array}$ & $\begin{array}{l}\text { Stage IIIB, } \\
\text { IV }\end{array}$ & $\begin{array}{l}\text { Squamous cell, } \\
\text { adenocarcinoma or } \\
\text { undifferentiated, } \\
\text { large cell carcinoma }\end{array}$ & NR \\
\hline Sun Y 2013 & III & Chinese & $\begin{array}{l}\mathrm{D}: \text { docetaxel } 75 \mathrm{mg} / \mathrm{m}^{2} \\
\mathrm{~N}: \text { pemetrexed } 500 \\
\mathrm{mg} / \mathrm{m}^{2}\end{array}$ & $\begin{array}{l}\text { Stage IIIB, } \\
\text { IIIA, IV }\end{array}$ & $\begin{array}{l}\text { Adenocarcinoma, } \\
\text { squamous cell, } \\
\text { mixed cell } \\
\text { carcinoma }\end{array}$ & NR \\
\hline Wu YL 2013 & III & Chinese & $\begin{array}{l}\text { D: docetaxel } 75 \mathrm{mg} / \mathrm{m}^{2} \\
\mathrm{~N}: \text { pemetrexed } 500 \\
\mathrm{mg} / \mathrm{m}^{2}\end{array}$ & Stage III-IV & $\begin{array}{l}\text { Adenocarcinoma, } \\
\text { other (mixed cell } \\
\text { carcinoma) }\end{array}$ & NR \\
\hline
\end{tabular}

Notes: AUC: area under the curve; NR: not reported. 


\section{Sensitivity analysis}

The sensitivity analysis showed that the pooled results were not significantly changed after deleting each trial, which confirmed the rationality and reliability of our meta-analysis (Figure 4).

\section{Publication bias}

According to the result of Begg's test $(P=0.900)$, no publication bias existed in this meta-analysis.

\section{DISCUSSION}

To the best of our knowledge, this study is the first systematic review and meta-analysis to assess the risk of severe infections ( $\geq$ grade 3 ) in docetaxel-treated patients with NSCLC. A few meta-analyses have compared docetaxel to other drugs in the treatment of NSCLC. For example, Di BS et al. showed that docetaxel had a similar efficacy to pemetrexed in patients with advanced NSCLC, while docetaxel resulted in a higher rate of febrile neutropenia (grade 3-4), neutropenia, diarrhea, leukocytes, and alopecia toxicity and a lower rate of thrombocytopenia (grade 3-4) than did pemetrexed [21]. He X et al. also reported that docetaxel could improve both progressionfree survival and the overall response rate as a firstline treatment for patients with advanced NSCLC compared to vinca alkaloid; furthermore, docetaxel had a lower rate than vinca alkaloid of hematological and non-hematological toxicity (grade 3/4) [22]. Although these previous meta-analyses assessed the efficacy and some adverse events of docetaxel in the treatment of NSCLC, they did not comprehensively assess the risk of severe infections ( $\geq$ grade 3 ) in docetaxel-treated patients, thereby providing the rationale for conducting this systematic review.

Our systematic review and meta-analysis, which included 43 randomized controlled trials consisting of 12,447 participants, showed that docetaxel significantly increased the risk of severe infections ( $\geq$ grade 3 ) in patients with NSCLC. In addition to the overall analysis, we performed subgroup analyses on such factors as age, type of intervention, docetaxel

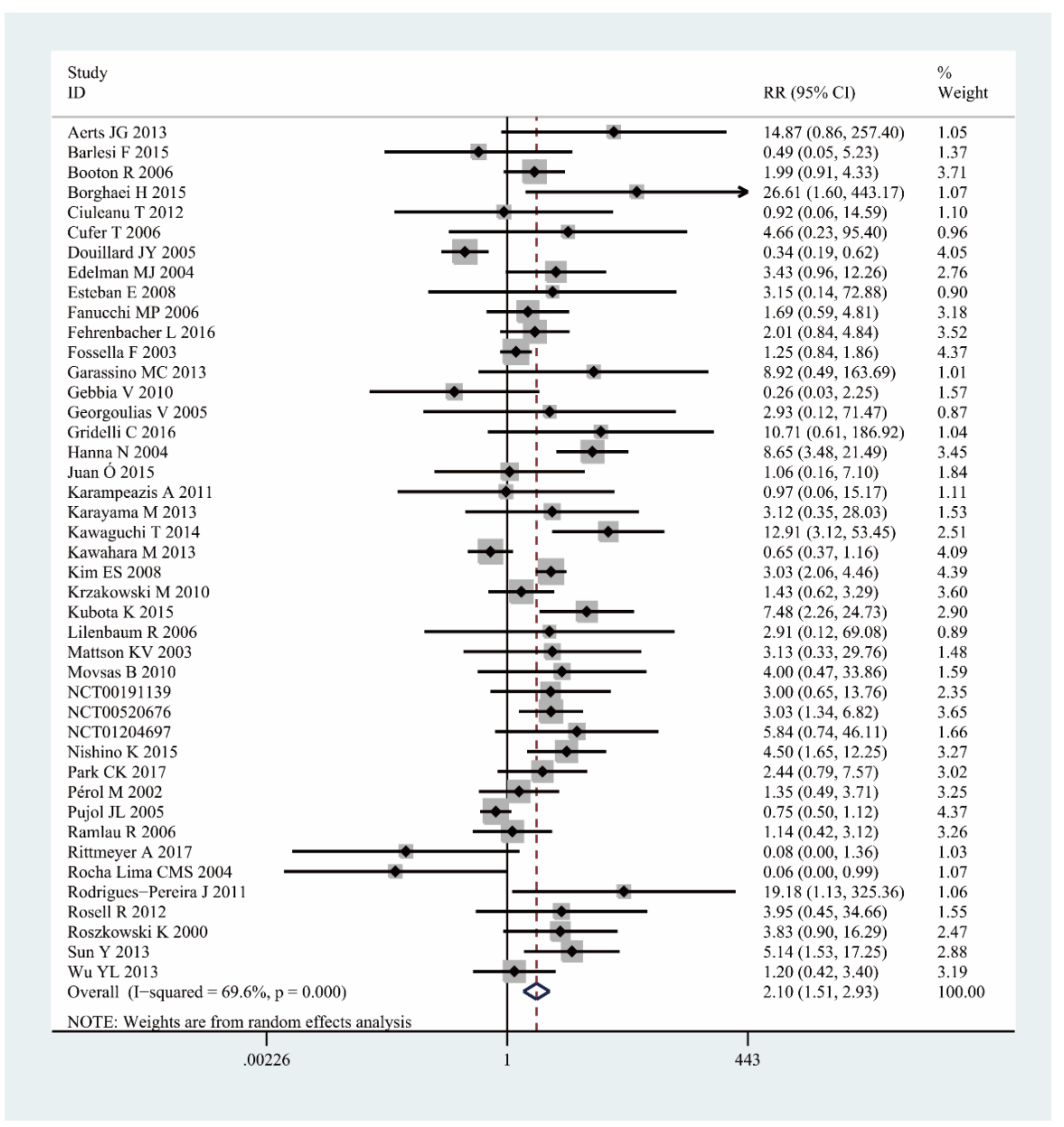

Figure 3: Relative risk and 95\% confidence interval for severe infections between the docetaxel group and the control group. 
dosage, and trial phase. While subgroup analyses based on age and intervention type gave results consistent with those of the overall meta-analysis, the subgroup analyses based on docetaxel dosage and trial phase produced slightly different outcomes. On the one hand, the docetaxel dosage $\geq 75 \mathrm{mg} / \mathrm{m}^{2}$ and phase III trial subgroups showed that docetaxel increased the risk of severe infections in NSCLC patients; on the other hand, no significant differences in severe infections were observed between the docetaxel group and the control group for the $<75 \mathrm{mg} / \mathrm{m}^{2}$ dosage and phase II trial subgroups. Although these latter subgroups showed some differences from the overall results, they were interpretable. It was previously reported that febrile neutropenia and non-neutropenic infections were associated with docetaxel dosage [63]. While a high dose of medicine will always carry a high risk of side effects, a lower dose $\left(<75 \mathrm{mg} / \mathrm{m}^{2}\right)$ is more likely to have a neutral impact on the risk of severe infections. Additionally, sample size may have influenced the results of the subgroup analysis, leading to the differences in the pooled results between the subgroups including 19 phase II trials and 2,138 participants and 24 phase III trials and 10,309 participants. Additionally, to assess the potential effect of drugs used in combination with docetaxel, a subgroup analysis was performed to differentiate studies testing docetaxel alone versus studies testing docetaxel-based combinations. Both the docetaxel alone subgroup and the docetaxel with other interventions subgroup revealed that docetaxel is associated with an increased risk of severe infections.

Although the results from this meta-analysis clearly indicate that docetaxel treatment is significantly associated with the risk of severe infections, the mechanism underlying these docetaxel-induced adverse reactions remains unknown. Kotsakis A et al. showed that most patients undergoing docetaxel treatment with nonneutropenic infections had an extremely low absolute number of peripheral blood lymphocytes, indicating that these patients likely developed impaired immune function [64]. Therefore, docetaxel-related severe infections are possibly due to a cytotoxic effect of docetaxel on the immune system. However, further studies are required to thoroughly explore this possible mechanism of docetaxelassociated infection.

As a result of recent studies [31, 37], immunotherapy has become a promising therapy for NSCLC and has provided an important breakthrough in the treatment of lung cancer. Common immunotherapy agents include anti-programmed cell death protein-1 (anti-PD-1), anti-programmed cell death-ligand 1 (anti-PD-L1) and cytotoxic T-lymphocyte antigen-4 (CTLA-4) therapeutics. For example, two anti-PD-1 therapies (nivolumab and pembrolizumab) and one
anti-PD-L1 agent (atezolizumab) are in the advanced stages of development as treatments for advanced or metastatic NSCLC [65]. In clinical trials, nivolumab was shown to significantly improve overall survival, response rate, and progression-free survival and to have a lower incidence of treatment-related adverse events (grade 3 or 4 ) than docetaxel in cases of advanced squamous cell NSCLC [31]. Atezolizumab also led to much better survival outcomes and a lower incidence of treatment-related adverse events (grade 3-4) than docetaxel in the treatment of NSCLC patients [37]. Therapeutic strategies for lung cancer will likely change in response to the successful clinical application of PD-1 immune checkpoint blockade [65]. Although immunotherapy has become a promising therapy for NSCLC, its development still faces several significant challenges. First, immunotherapy cannot be used as first-line treatment and does not work well with other effective treatments. Second, immunotherapy with anti-PD-1/anti-PD-L1 agents may increase the risk of hyper-progressive disease $[66,67]$, and PD-1 inhibitors might increase the risk of pneumonitis compared to common chemotherapy agents [68]. Third, the high cost of immunotherapies such as antiPD-1 agents for NSCLC treatment [69] inhibits their widespread use, especially in developing countries. Thus, although immunotherapy strategies have progressed, the chemotherapy agent docetaxel, with clearly demonstrated effects and good tolerability, will continue to have a positive effect on NSCLC treatment.

Chemotherapy agents for cancer treatment have benefits and harms. Most patients overestimate the intervention benefits and underestimate the harm associated with treatment [70]. Moreover, clinicians tend to underestimate the harm associated with medical treatments while overestimating their benefit [71]. Thus, assessments of adverse events associated with chemotherapy drugs are important for guiding the decision-making process in cancer treatment. Severe adverse events often result in treatment interruption or discontinuation and can even lead to hospitalization, disabilities and death. Information on adverse events can provide important reference material for clinical decision-making. Therefore, our systematic review and meta-analysis, which revealed that docetaxel is associated with an increased risk of severe infections, could provide clinicians with useful information to select the most appropriate treatment option for individual patients. Thus, our data should help guide treatment plans for NSCLC patients receiving docetaxel, with a positive effect on patient outcomes.

There are several strengths of our systematic review and meta-analysis. One, our study is the first systematic review and meta-analysis to assess the risk of severe infections ( $\geq$ grade 3 ) in docetaxel-treated patients with NSCLC. Two, this systematic review 
and meta-analysis included 43 trials with 12,447 participants; these high numbers significantly increase the statistical power and ensure the reliability of the results. Three, we performed a subgroup analysis to differentiate studies testing docetaxel alone versus studies testing docetaxel-based combinations and found that docetaxel both alone and combined with other interventions is associated with an increased risk of severe infections.

Several limitations are inherent to our systematic review and meta-analysis. We did not perform a subgroup analysis according to tumor histology, performance status or race because of a lack of available data. In addition, the risk of severe infections associated with docetaxel was estimated in phase II and III randomized controlled trials; thus, the real risk to patients with comorbidities and a poor performance status may be higher. Moreover, most of the included trials were open-label studies, in which clinicians or other investigators could have easily known whether docetaxel led to severe infection, resulting in bias. Additionally, the heterogeneity was significant in our systematic review.

Our systematic review and meta-analysis suggest that docetaxel is significantly related to the risk of severe infections during the treatment of NSCLC patients. Early in the treatment process, clinicians should examine docetaxel-treated patients for any signs of infection in order to maximize the therapeutic benefit of this drug. Future research should explore the mechanism by which docetaxel leads to infection and determine ways to reduce this elevated risk of severe infections.
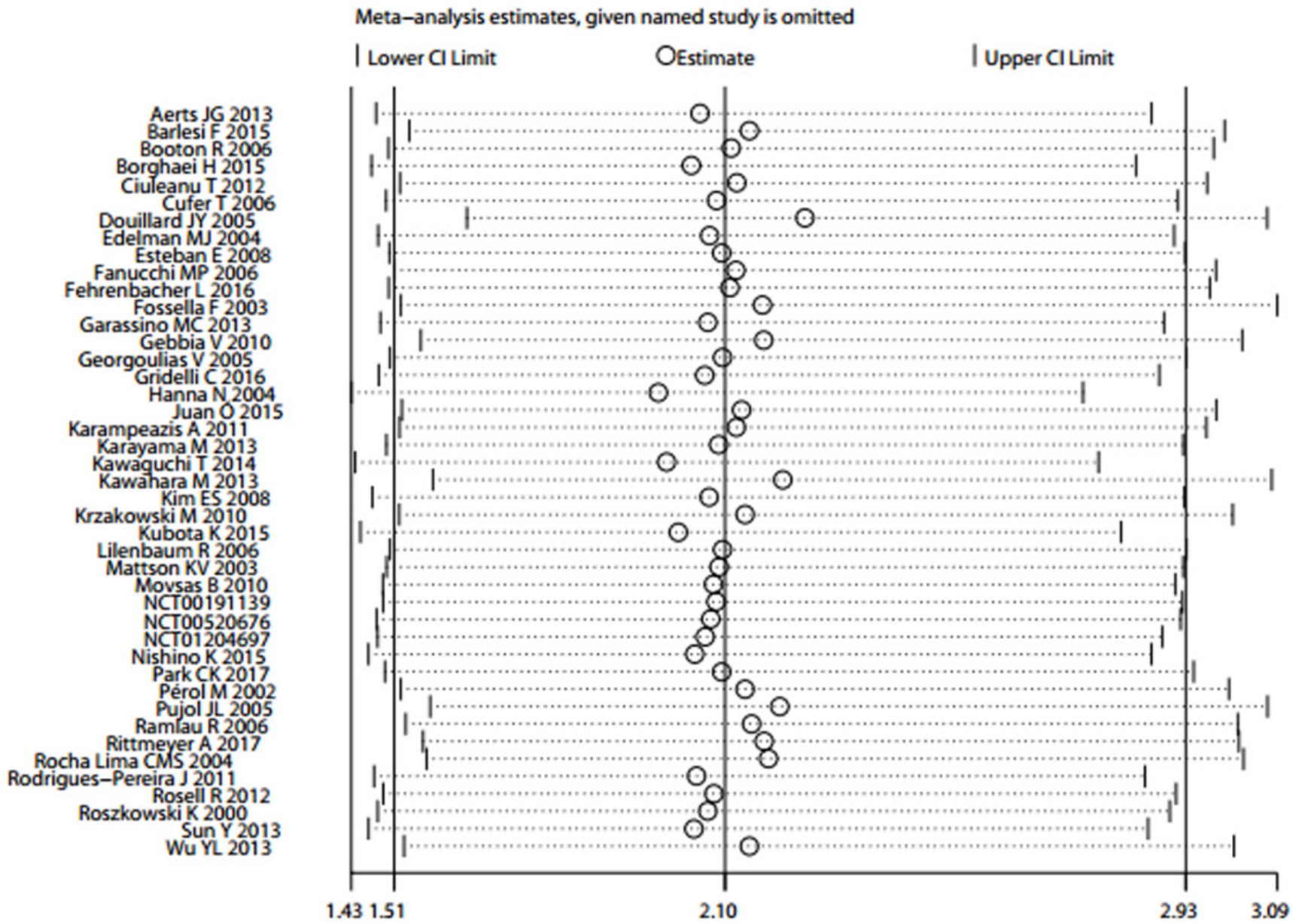

Figure 4: Sensitivity analysis of severe infections in patients with non-small cell lung cancer treated with docetaxel. 
Table 2: Subgroup analysis results

\begin{tabular}{|c|c|c|c|c|c|c|c|c|}
\hline \multirow[t]{2}{*}{ Subgroup } & \multirow{2}{*}{$\begin{array}{l}\text { Trials } \\
\text { (n) }\end{array}$} & \multicolumn{2}{|c|}{ No. of severe infections } & \multicolumn{2}{|c|}{ No. of participants } & RR $(95 \% \mathrm{CI})$ & \multirow[t]{2}{*}{$I^{2}$} & \multirow[t]{2}{*}{$P$-value } \\
\hline & & Docetaxel & Control & Docetaxel & Control & & & \\
\hline \multicolumn{9}{|l|}{ Age } \\
\hline$\geq 60$ & 24 & 279 & 112 & 3,642 & 3,193 & $\begin{array}{ll}2.03 & (1.37, \\
3.01) & \end{array}$ & $53.8 \%$ & 0.000 \\
\hline$<60$ & 19 & 288 & 155 & 2,842 & 2,770 & 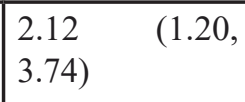 & $79.7 \%$ & 0.010 \\
\hline \multicolumn{9}{|l|}{ Intervention } \\
\hline $\begin{array}{l}\text { Docetaxel } \\
\text { without other } \\
\text { interventions }\end{array}$ & 15 & 250 & 68 & 2,438 & 2,427 & $\begin{array}{ll}3.26 & (2.12, \\
5.00) & \end{array}$ & $37.3 \%$ & 0.000 \\
\hline $\begin{array}{l}\text { Docetaxel } \\
\text { with other } \\
\text { interventions }\end{array}$ & 28 & 317 & 199 & 4,046 & 3,536 & $\begin{array}{ll}1.62 & (1.09, \\
2.39) & \end{array}$ & $67.2 \%$ & 0.016 \\
\hline \multicolumn{9}{|c|}{ Dose of docetaxel } \\
\hline$\geq 75 \mathrm{mg} / \mathrm{m}^{2}$ & 33 & 469 & 231 & 5,679 & 5,178 & $\begin{array}{ll}2.00 & (1.40, \\
2.87) & \end{array}$ & $68.6 \%$ & 0.000 \\
\hline$<75 \mathrm{mg} / \mathrm{m}^{2}$ & 10 & 98 & 36 & 805 & 785 & $\begin{array}{ll}2.34 & (0.91, \\
6.03) & \end{array}$ & $75.3 \%$ & 0.077 \\
\hline \multicolumn{9}{|l|}{ Phase of trial } \\
\hline II & 19 & 125 & 92 & 1,083 & 1,055 & \begin{tabular}{|ll}
1.69 & $(0.97$, \\
$2.96)$ &
\end{tabular} & $64.7 \%$ & 0.064 \\
\hline III & 24 & 442 & 175 & 5,401 & 4,908 & $\begin{array}{l}2.45 \quad(1.63, \\
3.69) \quad\end{array}$ & $70.6 \%$ & 0.000 \\
\hline
\end{tabular}

\section{METHODS}

We reported this systematic review according to the Preferred Reporting Items for Systematic Reviews and Meta-Analyses (PRISMA) guidelines [72].

\section{Data sources and searches}

We performed a literature search of the PubMed, EMBASE and Cochrane Central Register of Controlled Trials (CENTRAL) databases (up to February 28, 2017) without any language restrictions using the following terms: "carcinoma, non small cell lung", "carcinomas, non-small-cell lung", "lung carcinoma, non-small-cell", "lung carcinomas, non-small-cell", "non-small-cell lung carcinomas", "nonsmall cell lung cancer", "non-smallcell lung carcinoma", "non small cell lung carcinoma", "carcinoma, non-small cell lung", "non-small cell lung cancer", "non small cell lung cancer", "docetaxel", "docetaxel trihydrate", "docetaxol", "docetaxel anhydrous", "N-debenzoyl-N-tert-butoxycarbonyl-10deacetyltaxol", "taxoltere metro", "taxotere", "NSC 628503", "RP 56976", "RP-56976", "random*" and "randomized controlled trial". Human subject and clinical trial restrictions were implemented in the searches. We also searched the www.clinicaltrials.gov website to access unpublished data. Moreover, we checked each reference listed in the included studies, relevant reviews, and guidelines to include any previously ignored papers. All titles and abstracts from the initial search were transferred to Endnote X7 software. 


\section{Study selection}

The study selection was performed using Endnote $\mathrm{X} 7$ software. We selected eligible trials according to the following criteria: (1) participants were patients with NSCLC; (2) participants were grouped into a docetaxeltreated group (with or without other interventions) and a control group (without docetaxel); (3) severe infection ( $\geq$ grade 3) was a measured outcome; and (4) study design was a randomized controlled trial. The exclusion criteria consisted of the following: (1) duplicate studies and studies without outcomes or original data; and (2) trials with no events in both the docetaxel group and control group. For publications of the same trial or patient cohort, we chose the latest publication with the most complete data.

\section{Risk of bias assessment}

The risk of bias of each included trial was independently assessed by two authors using the risk of bias assessment tool in Review Manager 5.3 software according to the Cochrane Handbook for Systematic Reviews of Interventions version 5.1 [73]. Six aspects were evaluated, including selection bias (random sequence generation and allocation concealment), performance bias (blinding of participants and personnel), detection bias (blinding of outcome assessment), attrition bias (incomplete outcome data), reporting bias (selective reporting) and other bias. Each aspect included three options (low risk of bias, high risk of bias, and unclear risk of bias) from which the authors could choose according to the content of the trial. All inconsistencies in this process were resolved by discussion.

\section{Data extraction}

In this systematic review and meta-analysis, infection was defined as a disease characterized by febrile neutropenia, non-specified infection, pneumonia or sepsis as reported by the trial. Severe infections ( $\geq$ grade 3) were graded using the National Cancer Institute Common Toxicity Criteria version 2 or version 3 . We created a standardized form using Microsoft Excel 2013 to extract data from all included studies. The data were independently extracted by two authors using the standardized form. We entered the following data into the form: the first author's name, publication year, sample size, description of patients (age, sex, and race), type of intervention, dose, trial phase, disease stage, tumor histology, severe infection ( $\geq$ grade 3 ) events and median follow-up. Additionally, we contacted the authors of the article when we encountered any unclear information. We resolved all disagreements in this process through discussion.

\section{Data analysis}

We performed all statistical analysis using Stata 14.0 software. Severe infection events were considered dichotomous data and were pooled using the RR and $95 \%$ CI. We judged significant results according to the $P$-value; a $P$-value less than 0.05 indicated a significant result. We assessed heterogeneity among included studies using the $I^{2}$ statistic. If significant heterogeneity was present $\left(I^{2}>50 \%\right)$, we performed a meta-analysis using the random effects model [73]. Otherwise, we selected the fixed effects model. Furthermore, subgroup analyses were conducted according to age, type of intervention, docetaxel dosage, and trial phase. Sensitivity analysis was performed to determine whether an individual study influenced the overall result. We assessed the influence of each study on the pooled results by sequentially deleting a single study. Metaregression was performed to investigate any potential covariates with a substantial impact on the heterogeneity among studies. We performed a meta-regression according to the following potential covariates: age, type of intervention, docetaxel dosage, and trial phase. In addition, we used Begg's test to examine publication bias, which is recommended by the Cochrane Handbook for Systematic Reviews of Interventions [73].

\section{Abbreviations}

RR: relative risk; CI: confidence interval; NSCLC: non-small cell lung cancer.

\section{AUTHOR CONTRIBUTIONS}

Q.D. and G.J. contributed to the design and conception of the study. Q.D., G.J. and S.L. collected the data and performed the analysis, Q.D. and Y.L. wrote the manuscript, Z.H. revised the manuscript, and Y.L. and Z.H. provided the financial support.

\section{CONFLICTS OF INTEREST}

The authors declare no potential conflicts of interest.

\section{FUNDING}

This study was funded by the Natural Science Foundation of Guangdong Province, China (2015A030313518), the Traditional Chinese Medicine Bureau Foundation of Guangdong Province, China (20151264, 20161139). 


\section{REFERENCES}

1. Torre LA, Siegel RL, Jemal A. Lung Cancer Statistics. Adv Exp Med Biol. 2016; 893:1-19. https://doi. org/10.1007/978-3-319-24223-1_1

2. Micke P, Mattsson JS, Djureinovic D, Nodin B, Jirstrom K, Tran L, Jonsson P, Planck M, Botling J, Brunnstrom H. The Impact of the Fourth Edition of the WHO Classification of Lung Tumours on Histological Classification of Resected Pulmonary NSCCs. J Thorac Oncol. 2016; 11: 862-72. https://doi.org/10.1016/j.jtho.2016.01.020

3. Zheng M. Classification and Pathology of Lung Cancer. Surg Oncol Clin N Am. 2016;25:447-68. https://doi. org/10.1016/j.soc.2016.02.003

4. Ramalingam S, Belani C. Systemic chemotherapy for advanced non-small cell lung cancer: recent advances and future directions. Oncologist. 2008; 13:5-13. https://doi. org/10.1634/theoncologist.13-S1-5

5. Pao W, Girard N. New driver mutations in non-small-cell lung cancer. Lancet Oncol. 2011; 12:175-80. https://doi. org/10.1016/S1470-2045(10)70087-5

6. Della Rocca G, Vetrugno L, Coccia C, Pierconti F, Badagliacca R, Vizza CD, Papale M, Melis E, Facciolo F. Preoperative Evaluation of Patients Undergoing Lung Resection Surgery: Defining the Role of the Anesthesiologist on a Multidisciplinary Team. J Cardiothorac Vasc Anesth. 2016; 30:530-38. https://doi. org/10.1053/j.jvca.2015.11.018

7. PORT Meta-analysis Trialists Group. Postoperative radiotherapy in non-small-cell lung cancer: systematic review and meta-analysis of individual patient data from nine randomised controlled trials. Lancet. 1998; 352:25763. https://doi.org/10.1016/S0140-6736(98)06341-7

8. Ettinger DS, Wood DE, Aisner DL, Akerley W, Bauman J, Chirieac LR, D’Amico TA, DeCamp MM, Dilling TJ, Dobelbower M, Doebele RC, Govindan R, Gubens MA, et al. Non-Small Cell Lung Cancer, Version 5.2017, NCCN Clinical Practice Guidelines in Oncology. J Natl Compr Canc Netw. 2017; 15:504-35. https://doi.org/10.6004/ jncen.2017.0050

9. Fulton B, Spencer CM. Docetaxel. A review of its pharmacodynamic and pharmacokinetic properties and therapeutic efficacy in the management of metastatic breast cancer. Drugs. 1996; 51:1075-92. https://doi. org/10.2165/00003495-199651060-00011

10. Du W, Hong L, Yao T, Yang X, He Q, Yang B, Hu Y. Synthesis and evaluation of water-soluble docetaxel prodrugs-docetaxel esters of malic acid. Bioorg Med Chem. 2007; 15:6323-30. https://doi.org/10.1016/j. bmc.2007.04.002

11. Van Poppel H. Recent docetaxel studies establish a new standard of care in hormone refractory prostate cancer. Can J Urol. 2005; 12:81-85.

12. Heinemann L, Simpson GR, Boxall A, Kottke T, Relph KL, Vile R, Melcher A, Prestwich R, Harrington KJ, Morgan R,
Pandha HS. Synergistic effects of oncolytic reovirus and docetaxel chemotherapy in prostate cancer. BMC Cancer. 2011; 11:221. https://doi.org/10.1186/1471-2407-11-221

13. Molina JR, Yang P, Cassivi SD, Schild SE, Adjei AA. Nonsmall cell lung cancer: epidemiology, risk factors, treatment, and survivorship. Mayo Clin Proc. 2008; 83:584-94. https:// doi.org/10.1016/S0025-6196(11)60735-0

14. Reck M, Popat S, Reinmuth N, De Ruysscher D, Kerr KM, Peters S, and ESMO Guidelines Working Group. Metastatic non-small-cell lung cancer (NSCLC): ESMO Clinical Practice Guidelines for diagnosis, treatment and followup. Ann Oncol. 2014; 25:iii27-39. https://doi.org/10.1093/ annonc/mdu199

15. Saloustros E, Georgoulias V. Docetaxel in the treatment of advanced non-small-cell lung cancer. Expert Rev Anticancer Ther. 2008; 8:1207-22. https://doi. org/10.1586/14737140.8.8.1207

16. Fossella FV, DeVore R, Kerr RN, Crawford J, Natale RR, Dunphy F, Kalman L, Miller V, Lee JS, Moore M, Gandara D, Karp D, Vokes E, et al. Randomized phase III trial of docetaxel versus vinorelbine or ifosfamide in patients with advanced non-small-cell lung cancer previously treated with platinum-containing chemotherapy regimens. The TAX 320 Non-Small Cell Lung Cancer Study Group. J Clin Oncol. 2000; 18:2354-62. https://doi.org/10.1200/ JCO.2000.18.12.2354

17. Shepherd FA, Dancey J, Ramlau R, Mattson K, Gralla R, O'Rourke M, Levitan N, Gressot L, Vincent M, Burkes R, Coughlin S, Kim Y, Berille J. Prospective randomized trial of docetaxel versus best supportive care in patients with non-small-cell lung cancer previously treated with platinum-based chemotherapy. J Clin Oncol. 2000; 18:2095-103. https://doi.org/10.1200/JCO.2000.18.10.2095

18. Lim HK, Kim KM, Jeong SY, Choi EK, Jung J. Chrysin Increases the Therapeutic Efficacy of Docetaxel and Mitigates Docetaxel-Induced Edema. Integr Cancer Ther. 2017; 16:496-504. https://doi. org/10.1177/153473541664518427151585

19. Bria E, Cuppone F, Ciccarese M, Nisticò C, Facciolo F, Milella M, Izzo F, Terzoli E, Cognetti F, Giannarelli D. Weekly docetaxel as second line chemotherapy for advanced non-small-cell lung cancer: meta-analysis of randomized trials. Cancer Treat Rev. 2006; 32:583-87. https://doi.org/10.1016/j.ctrv.2006.07.003

20. Clegg A, Scott DA, Hewitson P, Sidhu M, Waugh N. Clinical and cost effectiveness of paclitaxel, docetaxel, gemcitabine, and vinorelbine in non-small cell lung cancer: a systematic review. Thorax. 2002; 57:20-28. https://doi. org/10.1136/thorax.57.1.20

21. Di BS, Wei KP, Tian JH, Xiao XJ, Li Y, Zhang XH, Yu Q, Yang KH, Ge L, Huang WH, Zhang FW. Effectiveness and safety of pemetrexed versus docetaxel as a treatment for advanced non-small cell lung cancer: a systematic review and meta-analysis. Asian Pac J Cancer Prev. 2014; 15:3419-24. https://doi.org/10.7314/APJCP.2014.15.8.3419 
22. He X, Wang J, Li Y. Efficacy and safety of docetaxel for advanced non-small-cell lung cancer: a meta-analysis of Phase III randomized controlled trials. Onco Targets Ther. 2015; 8:2023-31. https://doi.org/10.2147/OTT.S85648

23. Booton R, Lorigan $\mathrm{P}$, Anderson H, Baka S, Ashcroft L, Nicolson M, O'Brien M, Dunlop D, O'Byrne K, Laurence V, Snee M, Dark G, Thatcher N. A phase III trial of docetaxel/carboplatin versus mitomycin $\mathrm{C} /$ ifosfamide/cisplatin (MIC) or mitomycin C/vinblastine/ cisplatin (MVP) in patients with advanced non-small-cell lung cancer: a randomised multicentre trial of the British Thoracic Oncology Group (BTOG1). Ann Oncol. 2006; 17:1111-19. https://doi.org/10.1093/annonc/mdl078

24. Hanna N, Shepherd FA, Fossella FV, Pereira JR, De Marinis F, von Pawel J, Gatzemeier U, Tsao TC, Pless M, Muller T, Lim HL, Desch C, Szondy K, et al. Randomized phase III trial of pemetrexed versus docetaxel in patients with non-small-cell lung cancer previously treated with chemotherapy. J Clin Oncol. 2004; 22:1589-97. https://doi. org/10.1200/JCO.2004.08.163

25. Kubota K, Sakai H, Katakami N, Nishio M, Inoue A, Okamoto H, Isobe H, Kunitoh H, Takiguchi Y, Kobayashi K, Nakamura Y, Ohmatsu H, Sugawara S, et al, and Tokyo Cooperative Oncology Group. A randomized phase III trial of oral S-1 plus cisplatin versus docetaxel plus cisplatin in Japanese patients with advanced non-small-cell lung cancer: TCOG0701 CATS trial. Ann Oncol. 2015; 26:140108. https://doi.org/10.1093/annonc/mdv190

26. Douillard JY, Gervais R, Dabouis G, Le Groumellec A, D'Arlhac M, Spaeth D, Coudert B, Caillaud D, Monnier A, Clary C, Maury B, Mornet M, Rivière A, et al. Sequential two-line strategy for stage IV non-small-cell lung cancer: docetaxel-cisplatin versus vinorelbine-cisplatin followed by cross-over to single-agent docetaxel or vinorelbine at progression: final results of a randomised phase II study. Ann Oncol. 2005; 16:81-89. https://doi.org/10.1093/ annonc/mdi013

27. Gebbia V, Lorusso V, Galetta D, Caruso M M, Palomba G, Riccardi F, Borsellino N, Carrozza F, Leo S, Ferraù F, Cinieri S, Mancuso G, Mancarella S, Colucci G. Firstline cisplatin with docetaxel or vinorelbine in patients with advanced non-small-cell lung cancer: a quality of life directed phase II randomized trial of Gruppo Oncologico Italia Meridionale. Lung Cancer. 2010; 69:218-24. https:// doi.org/10.1016/j.lungcan.2009.10.008

28. Rocha Lima CM, Rizvi NA, Zhang C, Herndon JE 2nd, Crawford J, Govindan R, King GW, Green MR, and Cancer Leukemia Group B. Randomized phase II trial of gemcitabine plus irinotecan or docetaxel in stage IIIB or stage IV NSCLC. Ann Oncol. 2004; 15:410-18. https://doi. org/10.1093/annonc/mdh104

29. Aerts JG, Codrington H, Lankheet NA, Burgers S, Biesma B, Dingemans AM, Vincent AD, Dalesio O, Groen HJ, Smit EF, and NVALT Study Group. A randomized phase II study comparing erlotinib versus erlotinib with alternating chemotherapy in relapsed non-small-cell lung cancer patients: the NVALT-10 study. Ann Oncol. 2013; 24:286065. https://doi.org/10.1093/annonc/mdt341

30. Barlesi F, Chouaid C, Crequit J, Le Caer H, Pujol JL, Legodec J, Vergnenegre A, Le Treut J, Fabre-Guillevin E, Loundou A, Auquier P, Simeoni MC, Thomas PA. A randomized trial comparing adjuvant chemotherapy with gemcitabine plus cisplatin with docetaxel plus cisplatin in patients with completely resected non-small-cell lung cancer with quality of life as the primary objective. Interact Cardiovasc Thorac Surg. 2015; 20:783-90. https://doi. org/10.1093/icvts/ivv050

31. Borghaei H, Paz-Ares L, Horn L, Spigel DR, Steins M, Ready NE, Chow LQ, Vokes EE, Felip E, Holgado E, Barlesi F, Kohlhäufl M, Arrieta O, et al. Nivolumab versus docetaxel in advanced nonsquamous non-small-cell lung cancer. N Engl J Med. 2015; 373:1627-39. https://doi. org/10.1056/NEJMoa1507643

32. Ciuleanu T, Stelmakh L, Cicenas S, Miliauskas S, Grigorescu AC, Hillenbach C, Johannsdottir HK, Klughammer B, Gonzalez EE. Efficacy and safety of erlotinib versus chemotherapy in second-line treatment of patients with advanced, non-small-cell lung cancer with poor prognosis (TITAN): a randomised multicentre, open-label, phase 3 study. Lancet Oncol. 2012; 13:300-08. https://doi.org/10.1016/S1470-2045(11)70385-0

33. Cufer T, Vrdoljak E, Gaafar R, Erensoy I, Pemberton K, and SIGN Study Group. Phase II, open-label, randomized study (SIGN) of single-agent gefitinib (IRESSA) or docetaxel as second-line therapy in patients with advanced (stage IIIb or IV) non-small-cell lung cancer. Anticancer Drugs. 2006; 17:401-09. https://doi.org/10.1097/01. cad.0000203381.99490.ab

34. Edelman MJ, Clark J, Chansky K, Albain K, Bhoopalam N, Weiss GR, Giguere JK, Kelly K, Crowley J, Gandara DR. Randomized phase II trial of sequential chemotherapy in advanced non-small cell lung cancer (SWOG 9806): carboplatin/gemcitabine followed by paclitaxel or cisplatin/ vinorelbine followed by docetaxel. Clin Cancer Res. 2004; 10:5022-26. https://doi.org/10.1158/1078-0432.CCR-040002

35. Esteban E, Villanueva N, Muñiz I, Fernández Y, Fra J, Luque M, Jiménez P, Llorente B, Capelan M, Vieitez JM, Estrada E, Buesa JM, Jiménez-Lacave A. Pulmonary toxicity in patients treated with gemcitabine plus vinorelbine or docetaxel for advanced non-small cell lung cancer: outcome data on a randomized phase II study. Invest New Drugs. 2008; 26:67-74. https://doi.org/10.1007/ s10637-007-9073-4

36. Fanucchi MP, Fossella FV, Belt R, Natale R, Fidias P, Carbone DP, Govindan R, Raez LE, Robert F, Ribeiro M, Akerley W, Kelly K, Limentani SA, et al. Randomized phase II study of bortezomib alone and bortezomib in combination with docetaxel in previously treated advanced non-small-cell lung cancer. J Clin Oncol. 2006; 24:5025- 


\section{3. https://doi.org/10.1200/JCO.2006.06.1853}

37. Fehrenbacher L, Spira A, Ballinger M, Kowanetz M, Vansteenkiste J, Mazieres J, Park K, Smith D, Artal-Cortes A, Lewanski C, Braiteh F, Waterkamp D, He P, et al, and POPLAR Study Group. Atezolizumab versus docetaxel for patients with previously treated non-small-cell lung cancer (POPLAR): a multicentre, open-label, phase 2 randomised controlled trial. Lancet. 2016; 387:1837-46. https://doi. org/10.1016/S0140-6736(16)00587-0

38. Fossella F, Pereira JR, von Pawel J, Pluzanska A, Gorbounova V, Kaukel E, Mattson KV, Ramlau R, Szczęsna A, Fidias P, Millward M, Belani CP. Randomized, multinational, phase III study of docetaxel plus platinum combinations versus vinorelbine plus cisplatin for advanced non-small-cell lung cancer: the TAX 326 study group. J Clin Oncol. 2003; 21:3016-24. https://doi.org/10.1200/ JCO.2003.12.046

39. Garassino MC, Martelli O, Broggini M, Farina G, Veronese S, Rulli E, Bianchi F, Bettini A, Longo F, Moscetti L, Tomirotti M, Marabese M, Ganzinelli M, et al, and TAILOR trialists. Erlotinib versus docetaxel as second-line treatment of patients with advanced non-small-cell lung cancer and wild-type EGFR tumours (TAILOR): a randomised controlled trial. Lancet Oncol. 2013; 14:981-88. https:// doi.org/10.1016/S1470-2045(13)70310-3

40. Georgoulias V, Ardavanis A, Tsiafaki X, Agelidou A, Mixalopoulou P, Anagnostopoulou O, Ziotopoulos P, Toubis M, Syrigos K, Samaras N, Polyzos A, Christou A, Kakolyris $\mathrm{S}$, et al. Vinorelbine plus cisplatin versus docetaxel plus gemcitabine in advanced non-small-cell lung cancer: a phase III randomized trial. J Clin Oncol. 2005; 23:2937-45. https://doi.org/10.1200/JCO.2005.04.016

41. Gridelli C, Chella A, Valmadre G, Allegrini G, Brighenti M, Bidoli P, Rossi A, Maione P, Migliorino MR, Ricciardi S, DE Marinis F. Second-line erlotinib or intermittent erlotinib plus docetaxel in male ex-smokers with squamous NSCLC: the TALISMAN randomized trial. Anticancer Res. 2016; 36:6535-40. https://doi.org/10.21873/anticanres. 11255

42. Juan Ó, Aparisi F, Sánchez-Hernández A, Muñoz-Langa J, Esquerdo G, García-Sánchez J, López A, Garde J, Giner V. Intercalated dosing schedule of erlotinib and docetaxel as a therapeutic strategy to avoid antagonism and optimize its benefits in advanced non-small-cell lung cancer. A randomized phase II clinical trial. Clin Lung Cancer. 2015; 16:193-99. https://doi.org/10.1016/j.cllc.2014.11.006

43. Karampeazis A, Vamvakas L, Agelidou A, Kentepozidis N, Chainis K, Chandrinos V, Vardakis N, Pallis AG, Christophyllakis C, Georgoulias V. Docetaxel vs. vinorelbine in elderly patients with advanced non-smallcell lung cancer: a hellenic oncology research group randomized phase III study. Clin Lung Cancer. 2011; 12:155-60. https://doi.org/10.1016/j.cllc.2011.03.015

44. Karayama M, Inui N, Kuroishi S, Yokomura K, Toyoshima M, Shirai T, Masuda M, Yamada T, Yasuda K, Suda T, Chida $\mathrm{K}$. Maintenance therapy with pemetrexed versus docetaxel after induction therapy with carboplatin and pemetrexed in chemotherapy-naïve patients with advanced non-squamous non-small-cell lung cancer: a randomized, phase II study. Cancer Chemother Pharmacol. 2013; 72:445-52. https:// doi.org/10.1007/s00280-013-2218-6

45. Kawaguchi T, Ando M, Asami K, Okano Y, Fukuda M, Nakagawa H, Ibata H, Kozuki T, Endo T, Tamura A, Kamimura M, Sakamoto K, Yoshimi M, et al. Randomized phase III trial of erlotinib versus docetaxel as second- or third-line therapy in patients with advanced non-small-cell lung cancer: Docetaxel and Erlotinib Lung Cancer Trial (DELTA). J Clin Oncol. 2014; 32:1902-08. https://doi. org/10.1200/JCO.2013.52.4694

46. Kawahara M, Atagi S, Komuta K, Yoshioka H, Kawasaki M, Fujita Y, Yonei T, Ogushi F, Kubota K, Nogami N, Tsuchiya M, Shibata K, Tomizawa Y, et al, and Japan Multinational Trial Organization. Carboplatin plus either docetaxel or paclitaxel for Japanese patients with advanced non-small cell lung cancer. Anticancer Res. 2013; 33:463137.

47. Kim ES, Hirsh V, Mok T, Socinski MA, Gervais R, Wu YL, Li LY, Watkins CL, Sellers MV, Lowe ES, Sun Y, Liao ML, Østerlind K, et al. Gefitinib versus docetaxel in previously treated non-small-cell lung cancer (INTEREST): a randomised phase III trial. Lancet. 2008; 372:1809-18. https://doi.org/10.1016/S0140-6736(08)61758-4

48. Krzakowski M, Ramlau R, Jassem J, Szczesna A, Zatloukal P, Von Pawel J, Sun X, Bennouna J, Santoro A, Biesma B, Delgado FM, Salhi Y, Vaissiere N, et al. Phase III trial comparing vinflunine with docetaxel in second-line advanced non-small-cell lung cancer previously treated with platinum-containing chemotherapy. J Clin Oncol. 2010; 28:2167-73. https://doi.org/10.1200/JCO.2009.23.4146

49. Lilenbaum R, Socinski MA, Altorki NK, Hart LL, Keresztes RS, Hariharan S, Morrison ME, Fayyad R, Bonomi P. Randomized phase II trial of docetaxel/irinotecan and gemcitabine/irinotecan with or without celecoxib in the second-line treatment of non-small-cell lung cancer. J Clin Oncol. 2006; 24:4825-32. https://doi.org/10.1200/ JCO.2006.07.4773

50. Mattson KV, Abratt RP, ten Velde G, Krofta K. Docetaxel as neoadjuvant therapy for radically treatable stage III non-small-cell lung cancer: a multinational randomised phase III study. Ann Oncol. 2003; 14:116-22. https://doi. org/10.1093/annonc/mdg009

51. Movsas B, Langer CJ, Ross HJ, Wang L, Jotte RM, Feigenberg S, Xu F, Huang CH, Monberg MJ, Obasaju CK. Randomized phase II trial of cisplatin, etoposide, and radiation followed by gemcitabine alone or by combined gemcitabine and docetaxel in stage III A/B unresectable non-small cell lung cancer. J Thorac Oncol. 2010; 5:673-79. https://doi.org/10.1097/JTO.0b013e3181d60e8f 20354453

52. Nishino K, Imamura F, Kumagai T, Katakami N, Hata A, Okuda C, Urata Y, Hattori Y, Tachihara M, Yokota S, Nishimura T, Kaneda T, Satouchi M, et al. A randomized 
phase II study of bevacizumab in combination with docetaxel or S-1 in patients with non-squamous nonsmall-cell lung cancer previously treated with platinum based chemotherapy (HANSHIN Oncology Group 0110). Lung Cancer. 2015; 89:146-53. https://doi.org/10.1016/j. lungcan.2015.05.022

53. Park CK, Oh IJ, Kim KS, Choi YD, Jang TW, Kim YS, Lee KH, Shin KC, Jung CY, Yang SH, Ryu JS, Jang SH, Yoo SS, et al. Randomized Phase III Study of Docetaxel Plus Cisplatin Versus Pemetrexed Plus Cisplatin as First-line Treatment of Nonsquamous Non-Small-cell Lung Cancer: A TRAIL Trial. Clin Lung Cancer. 2017; 18:e289-96. https:// doi.org/10.1016/j.cllc.2017.01.002

54. Pérol M, Léna H, Thomas P, Robinet G, Fournel P, Coste $\mathrm{E}$, Belleguic $\mathrm{C}$, Le Caer $\mathrm{H}$, Blanchon $\mathrm{F}$, Vergnenègre A, Vernejoux JM, Schuller-Lebeau MP, Pham E. Phase II randomized multicenter study evaluating a treatment regimen alternating docetaxel and cisplatin-vinorelbine with a cisplatin-vinorelbine control group in patients with stage IV non-small-cell lung cancer: GFPC 97.01 study. Ann Oncol. 2002; 13:742-47. https://doi.org/10.1093/ annonc/mdf 128

55. Pujol JL, Breton JL, Gervais R, Rebattu P, Depierre A, Morère JF, Milleron $\mathrm{B}$, Debieuvre $\mathrm{D}$, Castéra D, Souquet PJ, Moro-Sibilot D, Lemarié E, Kessler R, et al. Gemcitabine-docetaxel versus cisplatin-vinorelbine in advanced or metastatic non-small-cell lung cancer: a phase III study addressing the case for cisplatin. Ann Oncol. 2005; 16:602-10. https://doi.org/10.1093/annonc/mdi126

56. Ramlau R, Gervais R, Krzakowski M, von Pawel J, Kaukel E, Abratt RP, Dharan B, Grotzinger KM, Ross G, Dane G, Shepherd FA. Phase III study comparing oral topotecan to intravenous docetaxel in patients with pretreated advanced non-small-cell lung cancer. J Clin Oncol. 2006; 24:2800 07. https://doi.org/10.1200/JCO.2005.03.6491

57. Rittmeyer A, Barlesi F, Waterkamp D, Park K, Ciardiello F, von Pawel J, Gadgeel SM, Hida T, Kowalski DM, Dols MC, Cortinovis DL, Leach J, Polikoff J, et al, and OAK Study Group. Atezolizumab versus docetaxel in patients with previously treated non-small-cell lung cancer (OAK): a phase 3, open-label, multicentre randomised controlled trial. Lancet. 2017; 389:255-65. https://doi.org/10.1016/ S0140-6736(16)32517-X

58. Rodrigues-Pereira J, Kim JH, Magallanes M, Lee DH, Wang J, Ganju V, Martínez-Barrera L, Barraclough H, van Kooten M, Orlando M. A randomized phase 3 trial comparing pemetrexed/carboplatin and docetaxel/carboplatin as firstline treatment for advanced, nonsquamous non-small cell lung cancer. J Thorac Oncol. 2011; 6:1907-14. https://doi. org/10.1097/JTO.0b013e318226b5fa

59. Rosell R, Carcereny E, Gervais R, Vergnenegre A, Massuti B, Felip E, Palmero R, Garcia-Gomez R, Pallares C, Sanchez JM, Porta R, Cobo M, Garrido P, et al, and
Spanish Lung Cancer Group in collaboration with Groupe Français de Pneumo-Cancérologie and Associazione Italiana Oncologia Toracica. Erlotinib versus standard chemotherapy as first-line treatment for European patients with advanced EGFR mutation-positive non-small-cell lung cancer (EURTAC): a multicentre, open-label, randomised phase 3 trial. Lancet Oncol. 2012; 13:239-46. https://doi. org/10.1016/S1470-2045(11)70393-X

60. Roszkowski K, Pluzanska A, Krzakowski M, Smith AP, Saigi E, Aasebo U, Parisi A, Pham Tran N, Olivares R, Berille J. A multicenter, randomized, phase III study of docetaxel plus best supportive care versus best supportive care in chemotherapy-naive patients with metastatic or nonresectable localized non-small cell lung cancer (NSCLC). Lung Cancer. 2000; 27:145-57. https://doi.org/10.1016/ S0169-5002(00)00094-5

61. Sun Y, Wu YL, Zhou CC, Zhang L, Zhang L, Liu XY, Yu SY, Jiang GL, Li K, Qin SK, Ma SL, Han L, Quinlivan $\mathrm{M}$, et al. Second-line pemetrexed versus docetaxel in Chinese patients with locally advanced or metastatic nonsmall cell lung cancer: a randomized, open-label study. Lung Cancer. 2013; 79:143-50. https://doi.org/10.1016/j. lungcan.2012.10.015

62. Wu YL, Sun Y, Zhou CC, Zhang L, Yu SY, Ma SL, Han LL, Zhang XQ, Orlando M. Survival without common toxicity criteria grade $3 / 4$ toxicity following second-line treatment with pemetrexed for nonsquamous non-small cell lung cancer in Chinese patients. Chin Med J (Engl). 2013; 126:4624-28.

63. Miller VA. Trials of vinorelbine and docetaxel in the treatment of advanced non small-cell lung cancer. Clin Lung Cancer. 2000; 1:S24-26. https://doi.org/10.3816/ CLC.2000.s.005

64. Kotsakis A, Sarra E, Peraki M, Koukourakis M, Apostolaki S, Souglakos J, Mavromanomakis E, Vlachonikolis J, Georgoulias V. Docetaxel-induced lymphopenia in patients with solid tumors: a prospective phenotypic analysis. Cancer. 2000; 89:1380-86. https://doi.org/10.1002/10970142(20000915)89:6<1380::AID-CNCR23>3.0.CO;2-R

65. Sgambato A, Casaluce F, Sacco PC, Palazzolo G, Maione P, Rossi A, Ciardiello F, Gridelli C. Anti PD-1 and PDL-1 Immunotherapy in the Treatment of Advanced Non- Small Cell Lung Cancer (NSCLC): A Review on Toxicity Profile and its Management. Curr Drug Saf. 2016; 11:62-68. https://doi.org/10.2174/1574886311207040289 26412670

66. Champiat S, Dercle L, Ammari S, Massard C, Hollebecque A, Postel-Vinay S, Chaput N, Eggermont A, Marabelle A, Soria JC, Ferte C. Hyperprogressive Disease Is a New Pattern of Progression in Cancer Patients Treated by AntiPD-1/PD-L1. Clin Cancer Res. 2017; 23:1920-28. https:// doi.org/10.1158/1078-0432.ccr-16-1741

67. Kato S, Goodman AM, Walavalkar V, Barkauskas DA, Sharabi A, Kurzrock R. Hyper-progressors after 
Immunotherapy: Analysis of Genomic Alterations Associated with Accelerated Growth Rate. Clin Cancer Res. 2017; 23:4242-50. https://doi.org/10.1158/1078-0432. CCR-16-3133.

68. Wu J, Hong D, Zhang X, Lu X, Miao J. PD-1 inhibitors increase the incidence and risk of pneumonitis in cancer patients in a dose-independent manner: a meta-analysis. Sci Rep. 2017; 7:44173. https://doi.org/10.1038/srep44173

69. Tartari F, Santoni M, Burattini L, Mazzanti P, Onofri A, Berardi R. Economic sustainability of anti-PD-1 agents nivolumab and pembrolizumab in cancer patients: recent insights and future challenges. Cancer Treat Rev. 2016; 48:20-24. https://doi.org/10.1016/j.ctrv.2016.06.002

70. Hoffmann TC, Del Mar C. Patients' expectations of the benefits and harms of treatments, screening, and tests: a systematic review. JAMA Intern Med. 2015; 175:274-86. https://doi.org/10.1001/jamainternmed.2014.6016

71. Hoffmann TC, Del Mar C. Clinicians' Expectations of the Benefits and Harms of Treatments, Screening, and Tests: A Systematic Review. JAMA Intern Med. 2017; 177:407-19. https://doi.org/10.1001/jamainternmed.2016.8254

72. Moher D, Liberati A, Tetzlaff J, Altman DG, and PRISMA Group. Preferred reporting items for systematic reviews and meta-analyses: the PRISMA statement. Int J Surg. 2010; 8:336-41. https://doi.org/10.1016/j.ijsu.2010.02.007

73. Higgins JP, Green S, eds. Cochrane Handbook for Systematic Reviews of Interventions Version 5.1.0 [updated March 2011]. The Cochrane Collaboration, 2011. Available from www.cochrane-handbook.org. 